\title{
Volume and surface effects on two-photonic and three-photonic processes in dry co-doped upconversion nanocrystals
}

\author{
Bettina Grauel ${ }^{1}$, Christian Würth ${ }^{1}$, Christian Homann ${ }^{3}$, Lisa Krukewitt ${ }^{1, \dagger}$, Elina Andresen ${ }^{1}$, Janina Roik ${ }^{2}$, \\ Sebastian Recknagel ${ }^{2}$, Markus Haase ${ }^{3}(\bowtie)$, and Ute Resch-Genger ${ }^{1}(\bowtie)$ \\ ${ }^{1}$ Federal Institute for Materials Research and Testing (BAM), Division 1.2 Biophotonics, Richard-Willstaetter-Str. 11, 12489 Berlin, Germany \\ ${ }^{2}$ Federal Institute for Materials Research and Testing (BAM), Division 1.6 Inorganic Reference Materials, Richard-Willstaetter-Str. 11, 12489 Berlin, \\ Germany \\ ${ }^{3}$ Institute of Chemistry of New Materials, Department Biology/Chemistry, University Osnabrueck, Barbarastr. 7, 49076 Osnabrueck, Germany \\ ${ }^{\dagger}$ Present address: Department of Anesthesiology and Intensive Care Medicine, University Medical Center Rostock, Schillingallee 35, 18057 Rostock, \\ Germany
}

(C) The Author (s) 2021

Received: 23 February 2021 / Revised: 1 July 2021 / Accepted: 3 July 2021

\begin{abstract}
Despite considerable advances in synthesizing high-quality core/shell upconversion (UC) nanocrystals (NC; UCNC) and UCNC photophysics, the application of near-infrared (NIR)-excitable lanthanide-doped UCNC in the life and material sciences is still hampered by the relatively low upconversion luminescence (UCL) of UCNC of small size or thin protecting shell. To obtain deeper insights into energy transfer and surface quenching processes involving $\mathrm{Yb}^{3+}$ and $\mathrm{Er}^{3+}$ ions, we examined energy loss processes in differently sized solid core $\mathrm{NaYF}_{4}$ nanocrystals doped with either $\mathrm{Yb}^{3+}\left(\mathrm{YbNC}_{2} 20 \% \mathrm{Yb}^{3+}\right)$ or $\mathrm{Er}^{3+}\left(\mathrm{ErNC}^{2} \% \mathrm{Er}^{3+}\right)$ and co-doped with $\mathrm{Yb}^{3+}$ and $\mathrm{Er}^{3+}\left(\mathrm{YbErNC} ; 20 \% \mathrm{Yb}^{3+}\right.$ and $\left.2 \% \mathrm{Er}^{3+}\right)$ without a surface protection shell and coated with a thin and a thick $\mathrm{NaYF}_{4}$ shell in comparison to single and co-doped bulk materials. Luminescence studies at $375 \mathrm{~nm}$ excitation demonstrate backenergy transfer (BET) from the ${ }^{4} \mathrm{G}_{11 / 2}$ state of $\mathrm{Er}^{3+}$ to the ${ }^{2} \mathrm{~F}_{5 / 2}$ state of $\mathrm{Yb}^{3+}$, through which the red $\mathrm{Er}^{3+}{ }^{4} \mathrm{~F}_{9 / 2}$ state is efficiently populated. Excitation power density $(P)$-dependent steady state and time-resolved photoluminescence measurements at different excitation and emission wavelengths enable to separate surface-related and volume-related effects for two-photonic and threephotonic processes involved in UCL and indicate a different influence of surface passivation on the green and red $\mathrm{Er}^{3+}$ emission. The intensity and lifetime of the latter respond particularly to an increase in volume of the active UCNC core. We provide a threedimensional random walk model to describe these effects that can be used in the future to predict the UCL behavior of UCNC.
\end{abstract}

\section{KEYWORDS}

upconversion luminescence, core/shell nanoparticles, dopant concentration, lifetime, volume effect, surface quenching

\section{Introduction}

Spectrally converting lanthanide $\left(\mathrm{Ln}^{3+}\right)$ upconversion (UC) nanocrystals (NC; UCNC) have emerged as a new class of nearinfrared (NIR)-excitable inorganic luminescent reporters. Applications range from bioimaging, fluorescence assays, sensors in bioanalysis, photodynamic therapy, optogenetics, optical thermometry, high resolution microscopy as well as photovoltaics, lasers, and security barcodes [1-18] and fluorophores for imaging in the short wave-infrared (SWIR) $[19,20]$. The best studied systems up to now are nanocrystals based on $\mathrm{NaREF}_{4}$ host lattices $(\mathrm{RE}=$ rare-earth $)$ doped with the absorbing sensitizer/emitting activator ion pairs $\mathrm{Yb}^{3+} / \mathrm{Er}^{3+}$ and $\mathrm{Yb}^{3+} / \mathrm{Tm}^{3+}$ or less commonly $\mathrm{Yb}^{3+} / \mathrm{Ho}^{3+}$. These materials reveal upconversion luminescence (UCL) with several emission bands in the ultraviolet (UV), visible (vis), and NIR characteristic for the activator ion upon excitation of the $\mathrm{Yb}^{3+}$ ions at $978 \mathrm{~nm}$. For the commonly used relatively low dopant concentrations of about $18 \%-20 \% \mathrm{Yb}^{3+}$ and $1 \%-3 \% \mathrm{Er}^{3+}$ or $0.2 \%-0.5 \% \mathrm{Tm}^{3+}$, UCL of these co-doped materials is mainly governed by energy transfer UC (ETU) which involves metastable energy states of the dopant ions [21]. Since the lifetimes of the excited states of the lanthanide ions are in the microsecond regime, the ETU mechanism in these materials is more efficient than other two-photonic or multiphotonic processes [22]. At high excitation power densities $(P)$, however, saturation can occur, depending on dopant ion concentration as well as UCNC size, crystal phase, and particle architecture [23]. Moreover, the intensity of UCL and particle brightness can be largely increased by high $P$. Under high $P$ excitation, also dopant concentrations can be used that considerably exceed the traditional limits derived for bulk upconversion phosphors [17, 24-26].

Despite considerable advances in the synthesis of high quality core/shell nanoparticles (NPs), minimizing the incorporation of UCL-quenching high energy vibrators like $\mathrm{OH}$ groups into UCNC cores during particle synthesis and protecting emissive lanthanide ions from surface quenching by sufficiently thick surface shielding shells [26-30], the UC efficiencies of nanocrystals nevertheless remain still lower than those of the respective bulk materials. Such quenching effects, which can also affect the spectral distribution of UCL, are particularly pronounced for very 
small and ultrasmall UCNPs with sizes $\leq 10 \mathrm{~nm}$ or even $\leq 5 \mathrm{~nm}$, in water, and at low $P$ [31].

Commonly assumed UCL quenching pathways, which can influence the different emissive levels of the activator ion and hence the spectral distribution of UCL differently, are surfacerelated quenching by defects, surface ligands, and surrounding solvent molecules with high energy vibrational modes [10, 32, 33]. As UC relies on multistep energy transfer (ET) processes, ET between neighboring $\mathrm{Ln}^{3+}$ ions can in principle be enhanced by higher dopant ion concentrations. This can, however, open additional luminescence quenching channels like (excitation) energy migration followed by surface quenching and/or cross relaxation (CR) [34-36]. Hence, to realize a maximum quantum yield of UCL $\left(\Phi_{\mathrm{UC}}\right)$ and achieve an optimum particle brightness for a given UCNC size and application-relevant experimental conditions including UCNC environment and $P$ requires a compromise between the efficiency enhancement by ETU and the minimization of losses caused by concentration quenching and energy migration combined with surface quenching [26]. The latter can be tackled by the growth of a tight surface protecting shell of controlled and ideally homogeneous thickness. This can be, however, hampered by a preferential growth of the shell material [37], lattice mismatch between core and shell materials $[38,39]$, and partial intermixing of core and shell during the shelling procedure [40]. Also, to tune energy migration, an increasing number of advanced core-shell structures with sets of lanthanide ions incorporated into separated layers at precisely defined concentrations were designed [41-46]. Moreover, models to describe spatial ET and migration processes and to eventually predict optimum particle architectures have been developed [47].

The most-commonly used, most efficient, and best studied UC couple presents currently the $\mathrm{Yb}^{3+}-\mathrm{Er}^{3+}$ system. This system can effectively convert NIR excitation absorbed by the sensitizer $\mathrm{Yb}^{3+}$, populating its single ${ }^{4} \mathrm{~F}_{5 / 2}$ excited state, into green and red luminescence from the subsequently populated ${ }^{2} \mathrm{H}_{11 / 2} /{ }^{4} \mathrm{~S}_{3 / 2}$ and ${ }^{4} \mathrm{~F}_{9 / 2}$ energy levels of $\mathrm{Er}^{3+}$, involving two- and three-photonic processes [48-50]. The intensity ratio of the green and red emission depends on different parameters including host matrix (crystal phase), dopant ion concentration, $P$, matrix/surrounding, and UCNC size $[4,51,52]$. Commonly, an enhanced relative spectral contribution of the red emission to overall UCL, accompanied by an enhanced NIR emission, at the cost of the green emission at low $P$ is a sign for a strongly quenched UCL. Examples are small core UCNC with sizes of about $25 \mathrm{~nm}$ in water with its strongly quenching $\mathrm{OH}$ groups (luminescence quenching via multi-phonon relaxation (MPR)) [32] or very small core UCNC with sizes $<20 \mathrm{~nm}$ in an organic solvent like cyclohexane (strong surface related quenching) [53].

To obtain a deeper insight into the role of energy transfer and surface quenching processes involving the $\mathrm{Yb}^{3+}$ and $\mathrm{Er}^{3+}$ ions, we examined the energy loss processes in differently sized dry (powder) core $\beta-\mathrm{NaYF}_{4} \mathrm{NC}$ doped with either $\mathrm{Yb}^{3+}(\mathrm{YbNC})$ or $\mathrm{Er}^{3+}$ (ErNC) and co-doped with $\mathrm{Yb}^{3+}$ and $\mathrm{Er}^{3+}$ (YbErNC) and in the corresponding core/shell NC made with two different shell thicknesses. Although applications for UCNC typically involve UCNC dispersed in a solvent or liquid environment, we deliberately chose to work with powders, as this allows us to discern between solvent-related and ligand-related surface quenching effects. Therefore, $P$-dependent steady state and timeresolved photoluminescence measurements of these NC were done at different excitation wavelengths, i.e., at $375 \mathrm{~nm}\left(\mathrm{Er}^{3+}\right.$ excitation) and in the NIR (976-978 nm; excitation mainly of $\left.\mathrm{Yb}^{3+}\right)$ and at different emission wavelengths to probe different $\mathrm{Er}^{3+}$ energy levels. These studies were done in comparison to the respective bulk phosphors Yb-Bulk, Er-Bulk, and YbEr-Bulk doped with comparable $\mathrm{Yb}^{3+}$ and $\mathrm{Er}^{3+}$ concentrations of about $20 \%$ $\mathrm{Yb}^{3+}$ and $2 \% \mathrm{Er}^{3+}$ as used for the NC. To address these questions for typical UCNC we used a standard oleic acid/octadecene based synthesis using $\mathrm{NH}_{4} \mathrm{~F}$ as fluoride synthetic route for the preparation of the $\mathrm{YbNC}$, ErNC, and YbErNC core and core/shell samples detailed in the Electronic Supplementary Material (ESM). The influence of solvent molecules on UCL was bypassed by studying exclusively dry, i.e., powdered samples. Special emphasis was dedicated to distinguishing between surface- and volumerelated effects on the luminescence behavior of $\mathrm{Ln}^{3+}$-doped NCs. Specifically, we aimed to separate surface quenching effects on the (de)population dynamics of the ${ }^{4} \mathrm{~F}_{9 / 2}$ and ${ }^{2} \mathrm{H}_{11 / 2}{ }^{4} \mathrm{~S}_{3 / 2}$ energy levels of $\mathrm{Er}^{3+}$ related to ligands from volume related effects and their influence on the red to green intensity ratios and the efficiencies of two- and three-photonic population processes.

\section{Experimental}

\subsection{Reagents}

Purified oleic acid was purchased from Fisher Scientific, 1octadecene (technical grade, 90\%) from Alfa Caesar, ammonium fluoride and sodium oleate were obtained from Sigma Aldrich and hydrated rare-earth chloride from Treibacher Industrie AG, respectively. All materials were used as received.

\subsection{Bulk materials}

The micrometer-sized solid bulk phosphors used in this study for comparison purposes, i.e., hexagonal $\mathrm{NaYF}_{4}$ doped with $20 \% \mathrm{Yb}^{3+}$ (Yb-Bulk) or $2 \% \mathrm{Er}^{3+}$ (Er-Bulk) or co-doped with $18 \% \mathrm{Yb}^{3+}$ and $2 \% \mathrm{Er}^{3+}$ (YbEr-Bulk) were prepared by the group of Prof. Th. Jüstel (FH Münster, Steinfurt) and Dr. K. Krämer (University of Bern, Switzerland). These ligand free bulk materials, produced via a high temperature synthesis [10], present the most efficient upconversion materials.

\subsection{NC synthesis and structural analytical characterization}

Oleate capped $\beta-\mathrm{NaYF}_{4}$ core $\mathrm{NC}$ doped with $2 \% \mathrm{Er}^{3+}$ and/or $20 \%$ $\mathrm{Yb}^{3+}$ and the corresponding core/shell $\mathrm{NC}$ with a $\mathrm{NaYF}_{4}$ shell were prepared via a standard oleic acid/octadecene based synthesis using $\mathrm{NH}_{4} \mathrm{~F}$ as fluoride source [55-57] (see ESM for details). The size and crystal phase of all particles were characterized by transmission electron microscopy (TEM) and X-Ray powder diffraction $(\mathrm{XRD})$, respectively.

\subsection{Structural-analytical and analytical characterization of the NC}

XRD data of the nanocrystals were recorded with a PANalytical $\mathrm{X}$ 'pert Pro system using $\mathrm{Cu}-\mathrm{K} \alpha$ radiation. TEM images were taken with a JEOL JEM 2100 transmission electron microscope using $\mathrm{a} \mathrm{LaB}_{6}$ cathode and an acceleration voltage of $200 \mathrm{kV}$ and are shown in Figs. S1-S3 in the ESM.

\subsection{NC samples for luminescence measurements}

To study the influence of the surface passivation shell, single- and co-doped NCs with a core diameter of about $7 \mathrm{~nm}$ and shell thicknesses of around 1,2, and $3 \mathrm{~nm}$ were synthesized. In the following, only the results obtained for the sample with a $2 \mathrm{~nm}$ thick shell are shown for reasons of clarity. For the size study, unshelled NCs of increasing sizes up to $38 \mathrm{~nm}$ for the $\mathrm{Er}^{3+}$-singledoped, $30 \mathrm{~nm}$ for the $\mathrm{Yb}^{3+}, \mathrm{Er}^{3+}$-co-doped, and $52 \mathrm{~nm}$ for the $\mathrm{Yb}^{3+}$ single-doped NC were synthesized.

All NC and bulk samples were spectroscopically studied as 
powders. For the $P$-dependent measurements, a $0.5 \mathrm{~mm}$ thin quartz glass cuvette from Hellma $\mathrm{GmbH}$ and an empty cuvette of the same type for the blank measurement were used. For the timedependent measurements and photoluminescence excitation spectra, a different quartz glass cuvette from Hellma $\mathrm{GmbH}$ of comparable thickness was employed (these measurements were done with a different sample holder).

\subsection{Fourier transform infrared (FT-IR) absorption spectroscopy}

FT-IR spectra were acquired on a Nicolet Nexus FT-IR spectrometer (Thermo Electron Corporation) using an attenuated total reflectance (ATR) accessory. The spectra were recorded in the extinction mode in a wavenumber range of 4,000-400 $\mathrm{cm}^{-1}$. The background spectrum was recorded before each measurement, and consequently subtracted from the sample spectrum to obtain the blank-corrected IR spectra.

\subsection{Photoluminescence excitation spectra}

To investigate the different possible excitation pathways and identify the energy levels which contribute mostly to the population of an emission band, photoluminescence excitation spectra of the bulk material were recorded in $90^{\circ}$ geometry using an FSP920 spectrofluorometer from Edinburgh Instruments equipped with a continuous Xe lamp and a $\mu \mathrm{F}$ lamp $920 \mathrm{H}$ (pulse duration of $3 \mu \mathrm{s}$ ) and a red extended photomultiplier tube (PMT, Hamamatsu R2658P). The presented spectra were corrected for the wavelength-dependent spectral radiance of the light source using a calibrated reference detector. To avoid saturation of the detector, second-order peaks located at half the detection wavelength were not measured.

\subsection{Time-resolved luminescence measurements}

Luminescence decays were recorded using an FLS980 spectrofluorometer from Edinburgh Instruments, equipped with an electrically modulated $8 \mathrm{~W} 978 \mathrm{~nm}$ laser (providing $40 \mu \mathrm{s}$ square pulses) and a $100 \mathrm{~mW} 375 \mathrm{~nm}$ pulsed light-emitting diode (LED) (providing $5 \mu$ s square pulses) as excitation light sources and a red-extended PMT (R2658P from Hamamatsu) for luminescence detection. The powder samples were placed inside a flat quartz glass cuvette and excited at a $90^{\circ}$ geometry. All solid oleate-capped NCs show a strong background luminescence in the ultraviolet (UV) and visible (vis) when excited in the UV originating from organic compounds remaining on the particle surface from NC synthesis. This leads to sharp spikes (lifetimes $<10 \mathrm{~ns}$ ) in the luminescence decay measurements. This shortlived background emission is not shown in the decay graphs, as it is not associated with the $\mathrm{Ln}^{3+}$ emission decays studied here.

The decay curves were fitted using multi exponential $(N$ exponential) tail fits according to Eq. (1), yielding $N$ lifetime components $\tau_{i}$ and their amplitudes $B_{i}$. The fit was performed from the start/onset of the decay and the intensity-weighted mean lifetimes $\tau_{\text {int }}$ were obtained from the fit parameters using Eq. (2). This procedure avoids the need to consider lifetime components, because the intensity-weighted mean lifetime provides the average photon emission time.

$$
\begin{gathered}
I_{\text {tail }}(t)=\sum_{i=1}^{N} B_{i} \cdot e^{-\frac{t}{\tau_{i}}} \\
\tau_{\text {int }}=\frac{\sum_{i=1}^{N} B_{i} \cdot \tau_{i}^{2}}{\sum_{i=1}^{N} B_{i} \cdot \tau_{i}}
\end{gathered}
$$

\subsection{Time resolved emission spectra (TRES)}

TRES measurements were done with an Edinburgh FLS980 spectrofluorometer equipped with $375 \mathrm{~nm}$ and $978 \mathrm{~nm}$ pulsed lasers and a red-extended PMT. The luminescence decays were recorded at wavelengths between 500 and $700 \mathrm{~nm}$ using identical measurement conditions (monochromator slit width, measurement time, etc.). The data were corrected for the wavelength-dependent spectral responsivity of the detection channel and normalized to the green emitting band centered around $541 \mathrm{~nm}\left({ }^{4} \mathrm{~S}_{3 / 2} \rightarrow{ }^{4} \mathrm{I}_{15 / 2}\right)$.

\subsection{Integrating sphere spectroscopy-P dependent emission spectra}

For the P-dependent absolute emission measurements, a previously described custom-built integrating sphere setup was utilized [58]. This setup consists of a highly stable $8 \mathrm{~W} 976 \mathrm{~nm}$ laser diode as excitation light source providing a top hat beam profile for sample excitation. The excitation channel is equipped with two filter wheels with different neutral density filters for the stepwise attenuation of the $P$ to cover 3-4 orders of magnitude of $P$. The detection channel includes another filter wheel equipped with edge, bandpass, and neutral density filters placed in front of a silicon charge coupled device (CCD) used for the spectrally resolved detection of the transmitted and emitted photons. All spectra were corrected for the wavelength-dependent spectral responsivity of the instrument's detection channel.

\subsection{Reflectance measurements}

The diffuse reflectance spectra were recorded with an LS1050 from PerkinElmer. The bulk powders were filled in thin film quartz cells with a diameter of 2 inch matching the port diameter of the integrating sphere and the diffuse reflectance spectra were calculated relative to certified diffuse reflectance standards from sphere optics.

\section{Results and discussion}

To assess and quantify ET and luminescence quenching effects in UCNC, we examined the luminescence emission and excitation spectra and decay dynamics of small, i.e., $7 \mathrm{~nm}$-sized core $\mathrm{NC}$ and the corresponding core/shell YbNC, ErNC, and YbErNC, coated with either an about $1 \mathrm{~nm}$-thick or an about $3 \mathrm{~nm}$-thick $\mathrm{NaYF}_{4}$ passivation shell, as well as unshelled NC with sizes $\geq 20 \mathrm{~nm}$ and the single and co-doped micrometer-sized powders $\mathrm{Yb}$-Bulk, ErBulk, and YbEr-Bulk. A detailed overview of the NC samples is given in Table S1 in the ESM. The sizes were determined from TEM images (Figs. S1-S3 in the ESM) and the shell thicknesses were obtained from the different sizes of the core and core/shell NC. In the following, we will solely use rounded values for the shell thicknesses (1 and $3 \mathrm{~nm}$ ). Some measurements were also performed with $7 \mathrm{~nm}$ core $\mathrm{YbErNC}$ with a shell thickness of about $2 \mathrm{~nm}$. These results are included in this manuscript as well to selectively provide a brief insight into the photoluminescence features of larger NC.

To identify differences in the population dynamics we focused on the $\mathrm{Yb}^{3+}$ emission and the green and red $\mathrm{Er}^{3+}$ emission. The emission intensity and lifetime of the $\mathrm{Yb}^{3+}$ energy level ${ }^{2} \mathrm{~F}_{5 / 2}$, which can be excited at wavelengths from about 900 to $1,200 \mathrm{~nm}$, are known to be sensitive to surface quenching and particularly to quenching by high energy vibrators like -OH or by MPR $[28,32]$. The green $\left({ }^{4} \mathrm{~S}_{3 / 2}\right)$ and the red $\left({ }^{4} \mathrm{~F}_{9 / 2}\right) \mathrm{Er}^{3+}$ emission can be quenched by efficient $\mathrm{CR}$ at elevated $\mathrm{Er}^{3+}$ concentrations (concentration quenching) [26] and the ${ }^{4} \mathrm{~F}_{9 / 2}$ level can be populated via backenergy transfer (BET) from $\mathrm{Er}^{3+}$ to $\mathrm{Yb}^{3+}$ [59]. Moreover, the ${ }^{4} \mathrm{I}_{11 / 2}$ 
$\mathrm{Er}^{3+}$ energy level $(976 \mathrm{~nm})$ can be prone to quenching by OHgroups incorporated e.g., within the particles during synthesis as well as to surface quenching $[26,49]$ and to concentration quenching at elevated $\mathrm{Er}^{3+}$ concentrations [26]. To investigate possible excitation pathways and identify the energy levels which mostly contribute to the population of the green and red emissive $\mathrm{Er}^{3+}$ energy levels, emission spectra of all samples as well as luminescence excitation and diffuse reflectance spectra of the bulk materials Yb-Bulk, Er-Bulk, and YbEr-Bulk were recorded (Figs. 1 and 2).

\subsection{Excitation pathways in lanthanide-doped materials}

Figures $1(\mathrm{a})$ and $1(\mathrm{~b})$ representatively show the typical emission spectra of $\mathrm{YbErNC}$ with a core size of $7 \mathrm{~nm}$ shelled with a $\mathrm{NaYF}_{4}$ shell of $3 \mathrm{~nm}\left(d_{\mathrm{s}}=3 \mathrm{~nm}\right.$; smallest core size with thickest protection shell) and $30 \mathrm{~nm}$ unshelled YbErNC (largest unshelled $\mathrm{YbErNC}$ studied for this series). Due to excitation of $\mathrm{Er}^{3+}$ via ETU from $\mathrm{Yb}^{3+}$, these emission spectra are $P$-dependent. For low $P$, the emission spectra of both samples are very similar, with the larger unshelled YbErNC displaying a slightly higher red to green ratio (Fig. 1(a)). The difference in the red to green ratio of both samples drastically increases with increasing $P$ (Fig. 1(b)). Typically, an efficient multiphotonic population of an emissive $\mathrm{Er}^{3+}$ energy level is only possible when quenching processes are small for the energy levels involved in the feeding processes. For $\mathrm{Yb} / \mathrm{Er}$ co-doped materials the strong contribution of the red luminescence is coupled to a BET which can be probed via high energy excitation or NIR excitation at high $P$. Figures $1(\mathrm{c})$ and $1(\mathrm{~d})$ show the emission spectra of $\mathrm{Er}^{3+}$-doped and $\mathrm{Yb}^{3+} / \mathrm{Er}^{3+}$ co-doped bulk materials at $375 \mathrm{~nm}$ excitation. Er-Bulk displays a dominant green emission with only a small red contribution caused by nonradiative relaxation or $\mathrm{CR}$. In contrast, YbEr-Bulk shows a very prominent red emission originating from the dominating BET process.

To identify BET and possible $\mathrm{CR}$ contributions to the population of the ${ }^{4} \mathrm{~S}_{3 / 2}$ (green), ${ }^{4} \mathrm{~F}_{9 / 2}$ (red), and ${ }^{4} \mathrm{I}_{11 / 2}$ (976 nm) energy levels of $\mathrm{Er}^{3+}$ and the ${ }^{2} \mathrm{~F}_{5 / 2}$ energy level of $\mathrm{Yb}^{3+}$, we compare the results of the Kubelka-Munk analysis of the diffuse reflectance measurements of the bulk materials with the corresponding luminescence excitation spectra recorded at the emission wavelengths characteristic for these energy levels (see Fig. 2). The results of the Kubelka-Munk analysis are proportional to the oscillator strength of the ground state transitions. A deviation between the luminescence excitation spectrum and the ground state oscillator strength indicates the contribution of an additional ET pathway to the population of the respective emissive energy level. For the $540 \mathrm{~nm}$ emission, the excitation spectra of the single and co-doped bulk materials agree very well with the diffuse reflectance spectra, indicating the absence of an additional population process for this energy level. For the $655 \mathrm{~nm}$ emission, however, Er-Bulk shows similar results while the comparison of the corresponding spectra of YbEr-Bulk reveals a strong contribution of a BET process originating from higher $\mathrm{Er}^{3+}$ energy levels absorbing between 350 and $410 \mathrm{~nm}$. For $375 \mathrm{~nm}$ excitation, this results in an intensity increase of about a factor 50 (Fig. 2(b)). A contribution of BET is also reflected in the excitation spectrum recorded at $1,000 \mathrm{~nm}$ which corresponds to the ${ }^{2} \mathrm{~F}_{5 / 2}$ and ${ }^{4} \mathrm{I}_{11 / 2}$ energy levels of $\mathrm{Yb}^{3+}$ and $\mathrm{Er}^{3+}$, respectively. The increase in intensity relative to the other $\mathrm{Er}^{3+}$ transitions is not as pronounced as for the $655 \mathrm{~nm}$ emission. The intensity is, however, still
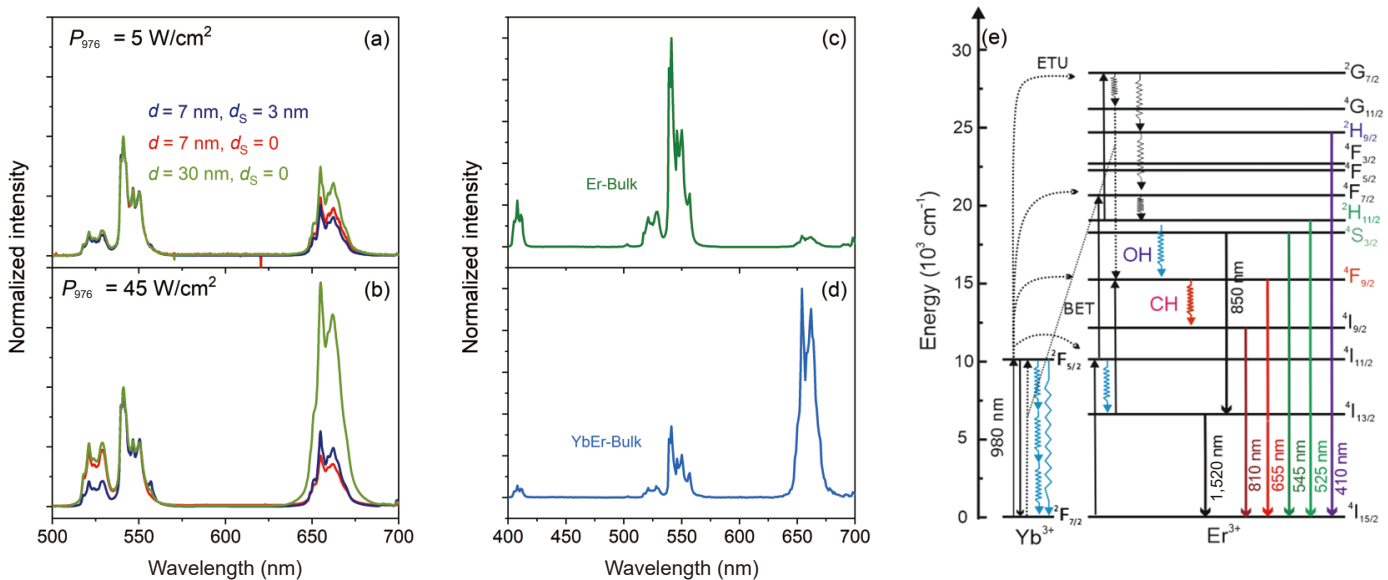

Figure 1 UCL spectra of solid $7 \mathrm{~nm}$ and $30 \mathrm{~nm}$ unshelled as well as core $/$ shell YbErNC (a) under $976 \mathrm{~nm}$ continuous wave excitation at low $P$ of $5 \mathrm{~W} / \mathrm{cm}^{2}$ and (b) under higher $P$ of $45 \mathrm{~W} / \mathrm{cm}^{2}$. The spectra are normalized to the green $\mathrm{Er}^{3+}$ emission at $540 \mathrm{~nm}$. Steady-state emission spectra of the bulk phosphors (c) Er-Bulk and (d) YbEr-Bulk, both under $375 \mathrm{~nm}$ pulsed excitation, using $5 \mu$ s pulses with a $100 \mathrm{~Hz}$ repetition rate. (e) Energy level diagram highlighting the different population and depopulation pathways of the green, red, and NIR-emissive $\mathrm{Er}^{3+}$ levels. ET: energy transfer, BET: back energy transfer, OH: non-radiative relaxation resonant with -OH vibrations, and $\mathrm{CH}$ : non-radiative relaxation resonant with $-\mathrm{CH}$ vibrations.
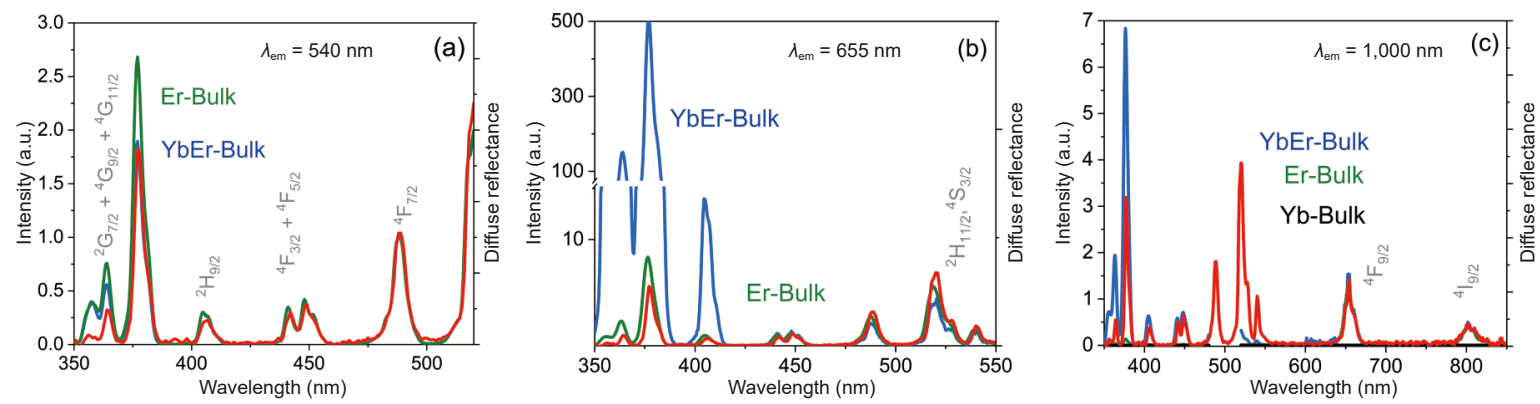

Figure 2 Spectrally corrected luminescence excitation spectra of the bulk phosphors YbEr-Bulk (blue), Er-Bulk (green), and Yb-Bulk (black) and Kubelka-Munk analysis of the diffuse reflectance spectrum of YbEr-Bulk (red). The excitation spectra of Er-Bulk and YbEr-Bulk were recorded at emission wavelengths of (a) $540 \mathrm{~nm}$, (b) $655 \mathrm{~nm}$, and (c) 1,000 nm. Second-order peaks were manually removed from the luminescence excitation spectra. 
considerably enhanced compared to Er-Bulk. Therefore, noticeable contributions from CR to the red emission band can be excluded as to be expected for the relatively low $\mathrm{Er}^{3+}$ doping concentration used in this study.

\subsection{Luminescence decay dynamics of differently sized} core and core/shell $\mathrm{YbNC}$ and ErNC compared to single doped bulk materials

The decay dynamics of the $\mathrm{Yb}^{3+}$ emission (excited at $978 \mathrm{~nm}$ and detected at $940 \mathrm{~nm}$ ) of differently sized core and small core/shell YbNC, which originates from the ${ }^{2} \mathrm{~F}_{5 / 2}$ state, are shown in Figs. 3(a) and 3(b). This figure reveals the expected increase in luminescence lifetime with increasing particle size from 7 to 52 $\mathrm{nm}$ for unshelled YbNC (Fig.3(a)). An even more significant lifetime prolongation is induced by the shielding of the surface of the small $7 \mathrm{~nm} \mathrm{YbNC}$ with an inert $\mathrm{NaYF}_{4}$ shell of increasing thickness (Fig. 3(b)).

These trends highlight the importance of surface quenching effects that can be suppressed by a sufficiently thick surface passivation shell as reported by several research groups $[27,31$, 49]. Nevertheless, the luminescence lifetime of the $52 \mathrm{~nm}$-sized unshelled $\mathrm{YbNC}(418 \mu \mathrm{s})$ is still considerably shorter than that of Yb-Bulk amounting to almost $2 \mathrm{~ms}$. Coating $7 \mathrm{~nm}$-sized YbNC with a $3 \mathrm{~nm}$ thick inert passivation shell, which is still thinner than the $5 \mathrm{~nm}$ shell thickness previously identified by us as sufficient for surface quenching protection of $3.7 \mathrm{~nm}$ core UCNC [31], leads to a more pronounced increase in the $\mathrm{Yb}^{3+}$ luminescence lifetime to about $1.3 \mathrm{~ms}$. Apparently, to approach the $\mathrm{Yb}^{3+}$ lifetime of $\mathrm{Yb}$ Bulk, a $3 \mathrm{~nm}$ surface passivation is more effective than a $\sim 400$-fold increase in volume. This underlines that for the $52 \mathrm{~nm}$ $\mathrm{YbNC}$ and a typical doping concentration of about $20 \%$ used here the energy diffusion length between neighboring $\mathrm{Yb}^{3+}$ ions is large enough to transport the excitation energy to the particle surface.

The decay dynamics of the $\mathrm{Er}^{3+}$ emission bands of differently sized unshelled and small core/shell ErNC, excited at $375 \mathrm{~nm}$ and detected at 540 and $655 \mathrm{~nm}$, which originate from the ${ }^{4} S_{3 / 2}$ and
${ }^{4} \mathrm{~F}_{9 / 2} \quad \mathrm{Er}^{3+}$ states, are shown in Figs. 3(c)-3(f). Additional measurements performed for the blue $\mathrm{Er}^{3+}$ emission at $410 \mathrm{~nm}$ are provided in Fig. S10 in the ESM. A comparison of the luminescence decay dynamics of the green and $\mathrm{red} \mathrm{Er}^{3+}$ emission of the differently sized unshelled ErNC excited at $375 \mathrm{~nm}$ with those of Er-Bulk, shown in Figs. 3(c) and 3(e), reveals a similar trend as observed for the $\mathrm{Yb}^{3+}$-doped particles, i.e., an increase in $\mathrm{Er}^{3+}$ lifetime with increasing particle size.

However, the decay kinetics of the green emission differs from those of the red. The lifetime of the green emission of the $38 \mathrm{~nm}$ unshelled ErNC (displayed in bright green) approaches that of ErBulk more closely than it does for the red emission (cf. Tab. S3 in the ESM). Also, for the green $\mathrm{Er}^{3+}$ emission, shelling of the small ErNC has a comparable effect on the luminescence lifetime to an increase in particle size (Figs. 3(c) and 3(d)), in contrast to the red emissive energy level, for which the decay dynamics are more strongly influenced by an increase in particle size (Fig. 3(e), $\tau_{\text {int }}=350 \mu$ s for the $38 \mathrm{~nm}$ ErNC) than by a protection shell (Fig. 3(f), $\tau_{\text {int }}=205 \mu$ s for the $7 \mathrm{~nm}$ core/shell ErNC with a $3 \mathrm{~nm}$ thick surface shell). Moreover, the lifetime of the green emission of the $7 \mathrm{~nm}$ ErNC coated with a $3 \mathrm{~nm}$-thick $\mathrm{NaYF}_{4}$ shell already closely approaches that of Er-Bulk. In contrast, the lifetime of the red emission of the $7 \mathrm{~nm}$ core $/ 3 \mathrm{~nm}$ shell ErNC excited at $375 \mathrm{~nm}$ $(205 \mu \mathrm{s})$ is still considerably shorter than that of Er-Bulk (641 $\mu \mathrm{s})$. Apparently, in contrast to the green $\mathrm{Er}^{3+}$ emission and the $940 \mathrm{~nm}$ $\mathrm{Yb}^{3+}$ luminescence, the $\mathrm{Er}^{3+}$ energy levels involved in the generation of the red emission are subject to non-radiative processes which cannot be efficiently suppressed by a surface protecting shell. The stronger influence of the particle volume or number of active ions suggests the occurrence of ET processes at the chosen low $\mathrm{Er}^{3+}$ concentration of $2 \%$ which particularly affect the red $\mathrm{Er}^{3+}$ emission. One explanation may be the formation of Er-Er pairs (clusters), that would favor luminescence quenching by CR [26]. However, for a recently studied $\mathrm{Er}^{3+}$ concentration series, a much stronger CR-related luminescence quenching was observed for the green-emitting ${ }^{4} S_{3 / 2}$ level than for the red ${ }^{4} \mathrm{~F}_{9 / 2}$
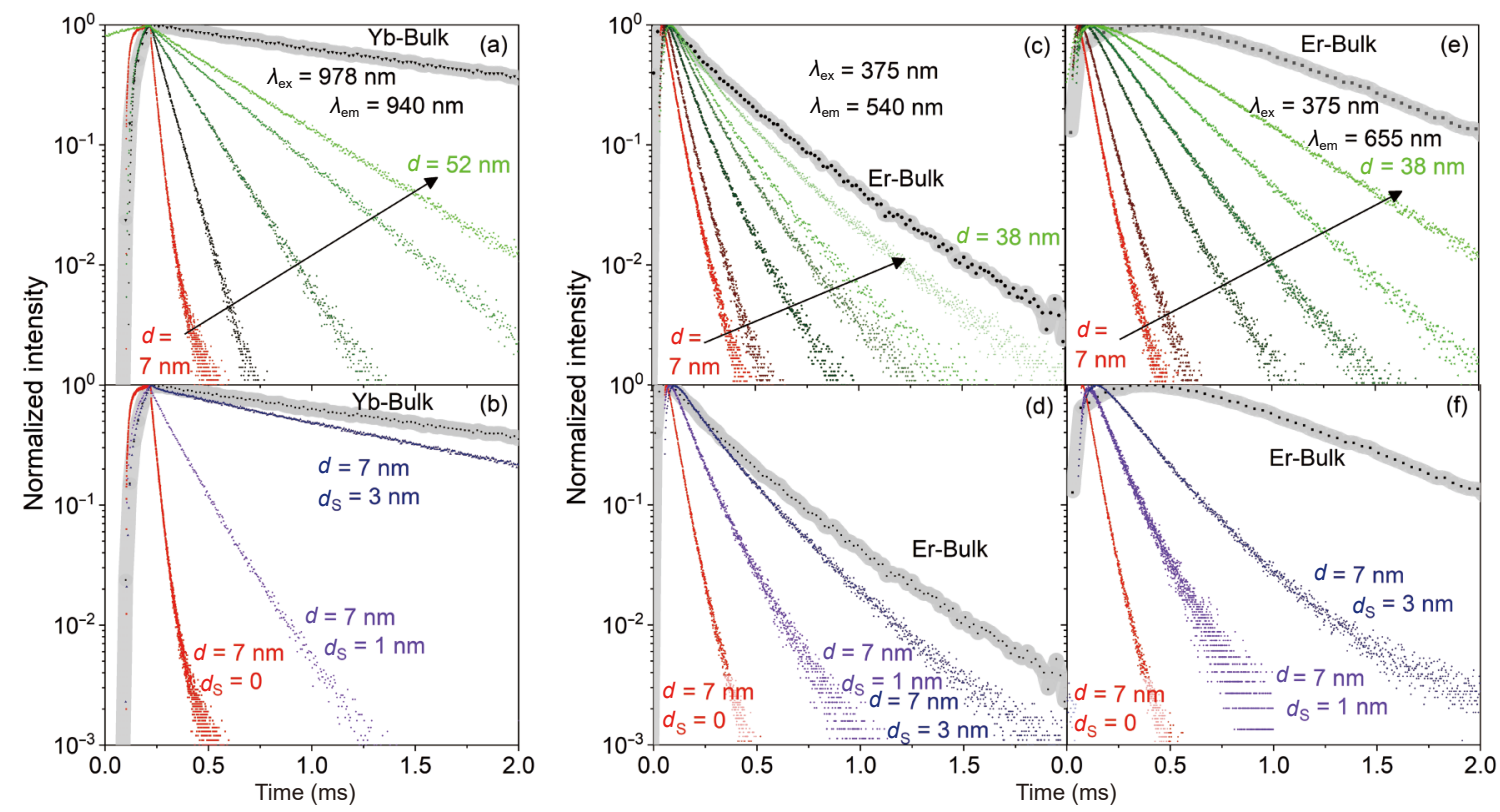

Figure 3 Normalized luminescence decay curves of the $\mathrm{Yb}^{3+}$ and $\mathrm{Er}^{3+}$ emissions of single-doped materials. (a) Normalized luminescence decay curves of the $940 \mathrm{~nm}$ $\mathrm{Yb}^{3+}$ emission of $7 \mathrm{~nm}$ - to $52 \mathrm{~nm}$-sized unshelled YbNC excited at $978 \mathrm{~nm}$ compared to the luminescence decay curve of Yb-Bulk. (b) Normalized luminescence decay curves of the $940 \mathrm{~nm} \mathrm{Yb}^{3+}$ emission of $7 \mathrm{~nm}$-sized core $\mathrm{YbNC}$ coated with a $1 \mathrm{~nm}$ and a $3 \mathrm{~nm}$ thick $\mathrm{NaYF}_{4}$ shell excited at $978 \mathrm{~nm}$ compared to the luminescence decay kinetics of Yb-Bulk. Normalized luminescence decay curves of the (c) $540 \mathrm{~nm}$ and (e) $655 \mathrm{~nm} \mathrm{Er}^{3+}$ emission bands of 7 to $38 \mathrm{~nm}$-sized unshelled ErNC excited at 375 $\mathrm{nm}$ compared to the luminescence decay curve of Er-Bulk. (d) Normalized luminescence decay curves of the $540 \mathrm{~nm}$ and (f) $655 \mathrm{~nm} \mathrm{Er^{3+ }}$ emission bands of $7 \mathrm{~nm}$ sized core ErNC coated with a $1 \mathrm{~nm}$ and a $3 \mathrm{~nm}$ thick $\mathrm{NaYF}_{4}$ shell excited at $375 \mathrm{~nm}$ compared to the luminescence decay curve of Er-Bulk. All samples were measured as powders. Table $\mathrm{S} 3$ in the ESM contains all NC sizes and their corresponding $\tau_{\text {int. }}$ 
level upon increasing the $\mathrm{Er}^{3+}$ concentration of unshelled as well as shelled YbErNC; for the red emissive $\mathrm{Er}^{3+}$ level, energy migration was identified as the major quenching mechanism [26]. For our particles, we exclude $\mathrm{CR}$ as nonradiative deactivation channel because of the low $\mathrm{Er}^{3+}$ doping concentration and the pronounced rise time of the luminescence decay curves.

One non-radiative deactivation pathway of UCL and the red emission can be surface quenching caused by the high-frequency vibrational modes of the surface ligands. Therefore, we measured the FT-IR spectra of representative NC that are shown in Fig. S5 in the ESM. The $\mathrm{C}-\mathrm{H}$ vibrations of the oleate surface ligand displayed in Fig. S5 in the ESM are located between 3,000 and $2,800 \mathrm{~cm}^{-1}$ and match very well with the energy gap of $2,900 \mathrm{~cm}^{-1}$ between the ${ }^{4} \mathrm{~F}_{9 / 2}$ and ${ }^{4} \mathrm{I}_{9 / 2} \mathrm{Er}^{3+}$ energy levels. The 2,956 $\mathrm{cm}^{-1}$ band originates from the $-\mathrm{CH}_{3}$ asymmetric stretching vibration and the bands at 2,851 and $2,921 \mathrm{~cm}^{-1}$ from the $-\mathrm{CH}_{2}-$ asymmetric and symmetric stretching vibrations, respectively. The IR band at $3,418 \mathrm{~cm}^{-1}$ which can affect the green $\mathrm{Er}^{3+}$ emission and the $\mathrm{Yb}^{3+}$ transition, is characteristic for the $-\mathrm{OH}$ stretching vibration and weak compared to the $-\mathrm{CH}$ vibrations.

To describe the observed quenching effects, we used a quenching layer model reported before by the Berry group and us $[49,53]$. For the calculation we modified this model in such a way that the volume averaged quenching efficiency induced by vibrations from surface adsorbed or coordinated molecules could be considered. The overall particle quenching efficiencies for different Förster radii were then compared to the experimentally determined quenching efficiencies of the NC relatively calculated vs. the bulk material. The ratio between the $-\mathrm{OH}$ and $-\mathrm{CH}$ vibrations in conjunction with the good match between the different vibrational bands of the surface bound molecules and the energy gaps between the different energy levels of $\mathrm{Er}^{3+}$ and $\mathrm{Yb}^{3+}$ result in a thicker quenching layer for the red emission. The estimated average quenching layer thickness is directly proportional to the Förster distance $\left(R_{0}\right)$ as typical for ET processes. We estimate the quenching layer thickness of the green emission to around $2 \mathrm{~nm}$ and that of the red luminescence of $\mathrm{Er}^{3+}$ to about 3-4 $\mathrm{nm}$ (see Fig. S7 in the ESM). These Förster radii determined from the size series are in good agreement with the effects observed for the shell series. For the green emission the Förster distance of $2 \mathrm{~nm}$ is slightly smaller than the thickness of the thickest passivation shell used in this study, but the distance for ET ranges up to $2 R_{0}$. This explains why with an approximately $3 \mathrm{~nm}$ thick shell, the quenching efficiency of the green emitting energy level reaches $25 \%$, whereas for the red emitting energy level, which is stronger affected by the interaction with the $-\mathrm{CH}$ vibrations resulting in a larger $R_{0}$, the quenching efficiencies are still in the range of $65 \%$ for the thickest surface shell. Similar effects were reported before for UCNC dispersed in different organic solvents $[32,53]$. The fact that the small NCs reveal an almost completely quenched emission also explains why the small ErNCs show similar decay curves of the green and red emission. For the larger less quenched NC, a different thickness of the quenching layer significantly influences the decay.

The comparison of the differently induced quenching efficiencies in $2 \% \mathrm{Er}^{3+}$ and $20 \% \mathrm{Yb}^{3+} 3-\mathrm{NaYF}_{4}$ (Fig. S7 in the ESM) clearly highlights that the $2 \% \mathrm{Er}^{3+}$ doping is small enough to reduce the influence of ET and that the luminescence quenching is induced by the organic surface coating. For $\mathrm{Yb}^{3+}$ the quenching layer model is not well suited because of the efficient energy migration between the $\mathrm{Yb}^{3+}$ ions. The theoretical $R_{0}$ considers the distance between an $\mathrm{Yb}^{3+}$ ion and its quencher, but due to the energy exchange between the ions (energy migration) this model cannot distinguish between ions located in the outer and inner particle. The resulting experimental quenching efficiency corresponds to an effective and giant $R_{0}$.

\subsection{Luminescence decay dynamics of core and core/shell}

\section{YbErNC compared to ErNC and YbEr-Bulk}

Subsequently the decay dynamics of the green and red $\mathrm{Er}^{3+}$ emission in YbErNC were assessed in comparison to those of ErNC and YbEr-Bulk. The $\mathrm{Yb}^{3+}$ ion with its single ${ }^{2} \mathrm{~F}_{5 / 2}$ excited state is the most frequently used sensitizer to realize brighter UCL fed by ETU from the initially excited $\mathrm{Yb}^{3+}$ to the emissive $\mathrm{Er}^{3+}$ ions. It has been shown that $\Phi_{\mathrm{UC}}$ correlates with the lifetime of the $\mathrm{Yb}^{3+}$ excited state [49], with a faster relaxation of the $\mathrm{Yb}^{3+}$ emission by energy migration to quenching sites at the particle surface diminishing UC efficiency. First, we performed this comparison for excitation at $375 \mathrm{~nm}$. Thereby, the $\mathrm{Er}^{3+}$ ions are directly excited without exciting $\mathrm{Yb}^{3+}$, which can provide information on a possible influence of the co-doped $\mathrm{Yb}^{3+}$ sensitizer ions on the intrinsic $\mathrm{Er}^{3+}$ luminescence in UC materials like a BET process from the initially excited $\mathrm{Er}^{3+}$ to the $\mathrm{Yb}^{3+}$ ions as suggested by the luminescence excitation spectra shown in Fig. 2. The resulting luminescence decays of the YbErNC are displayed in Fig. 4. To simplify this comparison visually, the decay curves of similar-size ErNC and Er-Bulk derived from Fig. 3 are also included in this figure (see lines in a lighter shade of the respective color).

As follows from Figs. 4(a)-4(f), the lifetimes of the green and red $\mathrm{Er}^{3+}$ emission of the co-doped particles are significantly shortened compared to the bulk material. The shelling-induced prolongation of the luminescence lifetime is more pronounced for the green emission (Figs. 4(a)-4(c)) than for the red luminescence (Figs. 4(d)-4(f)), due to the larger quenching layer. While $\tau_{\text {int }}$ of the green emission of a $7 \mathrm{~nm}$-sized YbErNC core approaches the lifetime of Er-Bulk and YbEr-Bulk already for a surface shell thickness of $3 \mathrm{~nm}, \tau_{\text {int }}$ of the red emission of this particle (122 $\left.\mu \mathrm{s}\right)$ still remains significantly shorter compared to the corresponding lifetimes of the red emission of Er-Bulk $(640 \mu \mathrm{s})$ and YbEr-Bulk $(540 \mu \mathrm{s})$. Moreover, for the red emission, a second effect linked to other (de)population pathways is clearly visible: The decay curves obtained for ErNC show a long rise time, whereas the luminescence decay profiles of the YbErNC lack this feeding process. We ascribe this observation to BET from the ${ }^{4} \mathrm{G}_{11 / 2}$ state of $\mathrm{Er}^{3+}$, excited at $375 \mathrm{~nm}$, to the ${ }^{2} \mathrm{~F}_{5 / 2}$ state of $\mathrm{Yb}^{3+}$, through which the red emissive ${ }^{4} \mathrm{~F}_{9 / 2}$ state of $\mathrm{Er}^{3+}$ can be then efficiently populated. For ErNC and Er-Bulk, this BET process is not possible, and the red emissive ${ }^{4} \mathrm{~F}_{9 / 2}$ state can only be populated via several non-radiative relaxation steps involving different $\mathrm{Er}^{3+}$ energy levels, which are responsible for the observed initial rise of the luminescence decay profiles. The lack of a rise time in the decay dynamics of the YbErNC indicates that the $\mathrm{Er}^{3+}-\mathrm{Yb}^{3+}$ BET is very fast (see also Fig. S9 in the ESM for YbEr-Bulk and Er-Bulk). By extracting the $\tau_{\text {int }}$ values from tail fits of the luminescence decays, thereby omitting a possible influence of a rise time, the trends of the decay times can be directly compared for the ErNC and YbErNC.

The data resulting for differently sized and shelled YbErNC are displayed in Figs. 4(m) and 4(n) and Fig. S11 in the ESM, and the data of the bulk materials is summarized in Fig. S9 in the ESM. Comparing the lifetime data reveals a slight prolongation of the lifetime of the red luminescence for ErNC lacking the BET process. This is attributed to the comparably long lived ${ }^{4} \mathrm{~S}_{3 / 2}$ state feeding the red luminescence. When the $\mathrm{Er}^{3+}$ red emissive energy level is directly excited at $635 \mathrm{~nm}$ this lifetime extension disappears which also underlines the role of BET for UCL. Apparently, the size vs. shell influence on both $\mathrm{Er}^{3+}$ luminescence bands is then comparable for ErNC and YbErNC.

To combine temporal and spectral information, TRES measurements were done. The time- and wavelength resolved data are shown in Figs. 4(g)-4(l) for a time window of the first millisecond $(1 \mathrm{~ms})$ after the $375 \mathrm{~nm}$ excitation pulse. The 

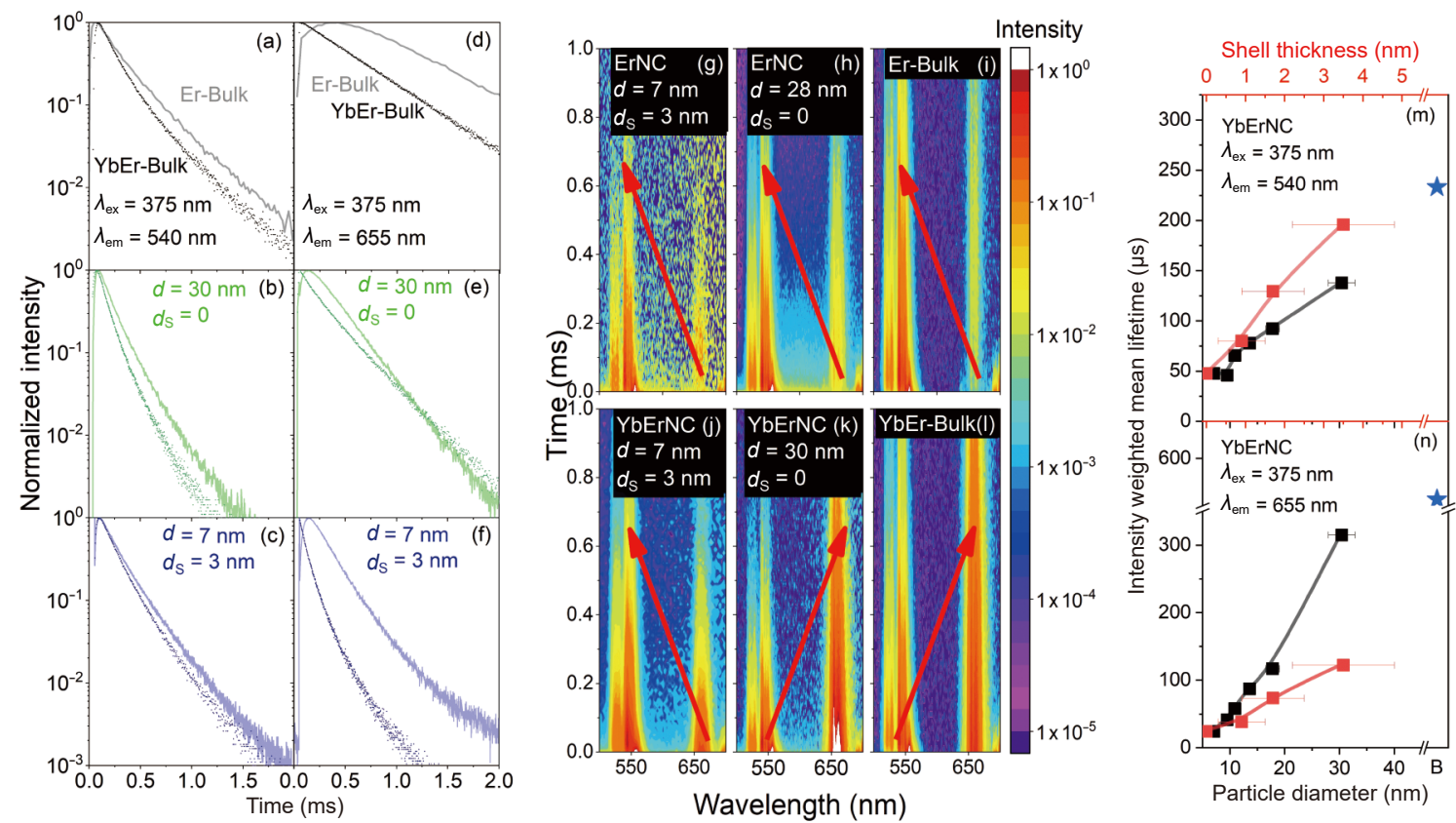

Figure 4 Luminescence of the YbErNC and YbEr-Bulk, compared to ErNC and Er-Bulk, at $375 \mathrm{~nm}$ excitation. (a)-(f) Normalized luminescence decay curves of bulk and nanocrystalline samples under $375 \mathrm{~nm}$ excitation. Er-single-doped materials are denoted as lines in a lighter, $\mathrm{Yb}^{3+}$-Er $\mathrm{E}^{3+}$-co-doped materials as dots in a darker color shade. Displayed are the $540 \mathrm{~nm}$ emissions of (a) bulk (black), (b) $30 \mathrm{~nm}$ unshelled YbErNC ( $\left.d_{s}=0\right)$ and $28 \mathrm{~nm}$ unshelled ErNC (green), (c) $7 \mathrm{~nm}$ NC with a $3 \mathrm{~nm}$ inert shell (navy), as well as the $655 \mathrm{~nm}$ emission of (d) bulk (black), (e) $30 \mathrm{~nm}$ unshelled YbErNC and $28 \mathrm{~nm}$ unshelled ErNC (green), and (f) $7 \mathrm{~nm}$ NC coated with $3 \mathrm{~nm}$ inert shell (navy). (g)-(l) TRES spectra of (g)-(i) ErNC and (j)-(l) YbErNC with a $7 \mathrm{~nm}$ core coated with a $3 \mathrm{~nm}$ shell, $28-30 \mathrm{~nm}$ unshelled NC without a shell, and bulk phosphors. All TRES data are spectrally corrected and normalized to the green emission band centered around $541 \mathrm{~nm}\left({ }^{4} \mathrm{~S}_{3 / 2} \rightarrow{ }^{4} \mathrm{I}_{15 / 2}\right)$. (m) and (n) Intensity weighted mean lifetimes obtained from fits of the luminescence decay curves according to Eq. (1) and Eq. (2). Black symbols indicate core size of unshelled YbErNC (bottom axis) and red symbols shell thickness of $7 \mathrm{~nm}$ core YbErNC (top axis). The blue star indicates the lifetime of YbEr-Bulk. Displayed are the $\tau_{\text {int }}$ of $Y b E r N C$ excited at $375 \mathrm{~nm}$ excitation $(\mathrm{m})$ recorded at $540 \mathrm{~nm}$ and $(\mathrm{n})$ at $655 \mathrm{~nm}$. The axis break of the time axis in (n) preserves clarity of the data shown.

normalized luminescence intensities are given in a logarithmic color scale. Since the intensities are normalized to the intensity at $541 \mathrm{~nm}$ in every panel, a direct comparison between the intensities of green- and red-emissive bands of one sample as well as between different samples is feasible. For better clarity, the different emission band ratios in Fig. 4 are indicated by red arrows. In addition to underlining the differences between the lifetimes of the NC and bulk materials, TRES analysis enables a time-resolved relative intensity comparison between the decay bands. As shown in Fig. 4, the red emission is significantly weaker than the green emission for $7 \mathrm{~nm}$ core/shell ErNC $\left(d_{\mathrm{S}}=3 \mathrm{~nm}\right.$, Fig. $\left.4(\mathrm{~g})\right)$, but not for the comparable core/shell YbErNC $\left(d_{\mathrm{S}}=3 \mathrm{~nm}\right.$, Fig. $\left.4(\mathrm{j})\right)$, even though the corresponding luminescence lifetimes of both samples are in the same range. This figure also confirms the very small contribution of the red emission for Er-Bulk (Fig. 4(i), cf. Fig. 1(c)), while the red emission of YbEr-Bulk is very strong (Fig. 4(1)), supporting the previously discussed population of the red emitting $\mathrm{Er}^{3+}$ level in the co-doped material through BET to $\mathrm{Yb}^{3+}$ ions (Fig. 2(b)). Moreover, whereas the TRES spectra of the 7 $\mathrm{nm}$ core/shell ErNC and the $28 \mathrm{~nm}$ unshelled ErNC are almost identical, except for the slightly longer decay of the red emission of the $28 \mathrm{~nm}$ core ErNC, the $7 \mathrm{~nm}$ core/shell YbErNC and the $30 \mathrm{~nm}$ unshelled YbErNC reveal opposite trends of the green and red lifetimes. The emission spectra resulting $60 \mu$ s after the excitation pulse (see Fig. S12 in the ESM) are comparable with the $978 \mathrm{~nm}$ continuous wave $(\mathrm{cw})$ emission spectra of both samples shown in Fig. 1. This underlines this effect for short pulsed and $\mathrm{cw}$ excitation and two different excitation pathways involving BET.

Figure 5 displays the time-resolved luminescence dynamics of YbErNC under $978 \mathrm{~nm}$ excitation, where the main population pathway of the emissive $\mathrm{Er}^{3+}$ energy levels is ETU. Figure 5(a) together with Figs. 3(a) and 3(b) reveals that for the single-doped $\mathrm{YbNC}$, shelling provides an almost ideal surface protection. For the $\mathrm{YbErNC}$, shelling significantly prolongs the $\mathrm{Yb}^{3+}$ emission, but not to the same extent as for $\mathrm{YbNC}$, since the ET between $\mathrm{Yb}^{3+}$ and $\mathrm{Er}^{3+}$ ions provides a significant energy loss channel for the ${ }^{2} \mathrm{~F}_{5 / 2}$ level of $\mathrm{Yb}^{3+}$. These results are confirmed by the trends of the $\tau_{\text {int }}$ displayed in Figs. 5(d) and 5(e). Contrary to the measurements performed at $375 \mathrm{~nm}$ excitation, the red emission appears to be equally prolonged by an increasing size and by a surface protection shell. The lifetime extension is especially pronounced for the short lived $410 \mathrm{~nm}$ emission (see Fig. S10 in the ESM). When considering the TRES measurements (Figs. 5(f)-5(h)), the opposite trends of the time-resolved relative intensities of the green and red emission under pulsed excitation, already observed under UV excitation, are visible for NIR excitation where ETU is the main population mechanism of the $\mathrm{Er}^{3+}$ energy levels.

Even though the $\tau_{\text {int }}$ of the $655 \mathrm{~nm}$ emission of the $7 \mathrm{~nm}$ core/shell $\left(d_{\mathrm{S}}=3 \mathrm{~nm} ; 301 \mu \mathrm{s}\right)$ and the $30 \mathrm{~nm}$ unshelled YbErNC $(351 \mu \mathrm{s})$ are very similar, the intensity of the red band in the TRES measurements of the former is much weaker than that of the green emission. Furthermore, the TRES data obtained at 978 and $375 \mathrm{~nm}$ excitation as well as the steady state emission spectra shown in Fig. 1, agree well. This suggests that the red emissive energy level of $\mathrm{Er}^{3+}$ is populated by different pathways for $\mathrm{YbErNC}$ of different core sizes. Surface shielding of the dry $\mathrm{Ln}^{3+} \mathrm{NC}$ is more efficient for the green than for the red emission. This can be explained by different sizes of the respective quenching layers as discussed above. The overall quenching efficiency of the red luminescence amounts to 0.6 for $30 \mathrm{~nm}$ particles and to 0.3 for the $7 \mathrm{~nm}$ core/shell $\mathrm{YbErNC}\left(d_{\mathrm{S}}=3 \mathrm{~nm}\right)$ while for the corresponding green emission bands, quenching efficiencies of 0.4 and 0.25 are found, respectively. These green-to-red quenching ratios of 0.6 and 0.83 must be considered to explain the different emission ratios. However, to explain the $P$-dependent emission behavior of the NC we additionally took another factor into account that affects the relative population of the red ${ }^{4} \mathrm{~F}_{9 / 2}$ level of $\mathrm{Er}^{3+}$ : the volume of the active core. 

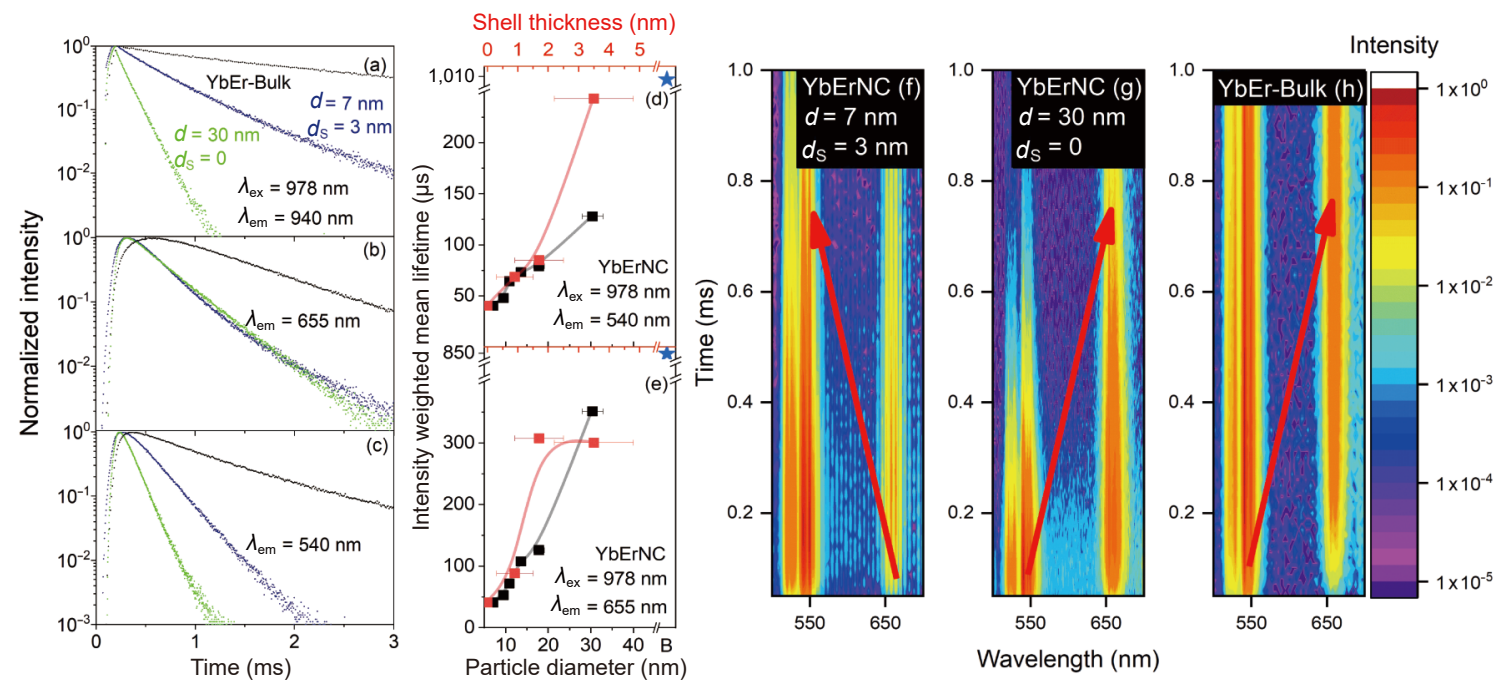

Figure 5 Luminescence of the YbErNC and YbEr-Bulk at $978 \mathrm{~nm}$ excitation. (a)-(c) Normalized luminescence decay curves, recorded under $978 \mathrm{~nm}$ excitation. Displayed are the luminescence decays of YbErNC and YbEr-Bulk recorded at (a) $\lambda_{e m}=940 \mathrm{~nm}$, (b) $\lambda_{\text {em }}=655 \mathrm{~nm}$, and (c) $\lambda_{\text {em }}=540 \mathrm{~nm}$. (d) and (e) $\tau_{\text {int }}$ of the studied NC with different sizes (black symbols, bottom axis) and shell thicknesses (red symbols, top axis), namely YbErNC excited at $978 \mathrm{~nm}$ and recorded at (d) $540 \mathrm{~nm}$ and (e) $655 \mathrm{~nm}$, respectively. The blue star indicates the lifetime of YbEr-Bulk. The axis breaks in (d) and (e) preserve clarity of the data shown. (f)-(h) TRES spectra of the $7 \mathrm{~nm}$ core $\mathrm{YbErNC}$ coated with a $3 \mathrm{~nm}$ shell, the $30 \mathrm{~nm}$ unshelled YbErNC, and YbEr-Bulk, measured under $978 \mathrm{~nm}$ excitation.

\subsection{Monte Carlo simulation}

A better understanding of the different mechanisms in the differently sized cores contributing to UCL at the same $P$ requires the modelling of the energy transfer processes in the YbErNC. A suitable model must consider the main parameters affecting the UC processes and (de)population pathways. Relevant for the occurrence and efficiency of energy transfer processes like ETU, BET, and CR are the crystal phase of the host matrix and the local symmetry faced by the lanthanide doping $\left(\mathrm{Yb}^{3+}\right.$ and $\left.\mathrm{Er}^{3+}\right)$ ions involved in UCL generation that determines the number of nearest neighbors and their distances. Models utilizing a hexagonal crystal phase of the host have been utilized, e.g., by Ledoux et al. in 2017 to model energy migration in $\mathrm{Yb}^{3+}-\mathrm{Tm}^{3+}-\mathrm{Gd}^{3+}-$ $\mathrm{Tb}^{3+}$ multilayer UCNP [60]. Villanueva-Delgado et al. combined Monte Carlo energy transfer modelling and a rate equation model for the simulation of $\mathrm{NaYF}_{4}$ : $\mathrm{Yb}^{3+}, \mathrm{Tm}^{3+}$ bulk material, where the $\mathrm{Yb}^{3+}$ and $\mathrm{Tm}^{3+}$ ions are placed randomly inside the $\beta-\mathrm{NaYF}_{4}$ host lattice at lattice-specific $(x, y, z)$ coordinates [61]. Alternatively, UCL features have been simulated with Monte Carlo kinetic models and experimentally derived material-specific UCL features. This has been done for example by Pawlik et al., who modelled ETU in $\mathrm{NaGdF}_{4}: \mathrm{Yb}^{3+}, \mathrm{Er}^{3+} \mathrm{UCNP}$ by considering clusters of $\mathrm{Yb}^{3+}$ and $\mathrm{Er}^{3+}$ ions, therefore omitting energy migration [62].

The choice of the crystal host determines UCL intensities, UCL efficiencies, and UCL lifetimes, as the local symmetry influences the luminescent centers, and the phonon energies enable coupling to surface vibrational modes for some hosts. Although the vibrational modes and phonon energies of the crystal phase are not included as parameters in our model, the usage of measured radiative rate constants, which contain also the information on non-radiative processes for the given crystal phase, can apparently at least partly compensate for local crystal field distortions and host-specific phonon energies.

Renero-Lecuna et al. and Aebischer et al. showed that distortions of local symmetry (cation disorder) are responsible for the efficient UCL in $\beta-\mathrm{NaYF}_{4}[63,64]$, not the number of nearest neighbors. This suggests that using a more easily accessible symmetry, e.g., a simple cubic instead of a more sophisticated hexagonal one while maintaining the $\beta$-material-specific ET and radiative rates, should be a valid simplification. Confusion with the a-phase of $\mathrm{NaYF}_{4}$, which is reported to have $\mathrm{Fm} \overline{3} \mathrm{~m}$ structure
[65], corresponding to a face-centered cubic symmetry, could be excluded.

In this work, we used a Monte Carlo model of the UC process in a $\mathrm{NaYF}_{4}: 20 \% \mathrm{Yb}^{3+}, 2 \% \mathrm{Er}^{3+}$ particle of radius $R$ based on a threedimensional random walk of the excited energy levels in the $\mathrm{Ln}^{3+}$ doped host crystal lattice. This model was originally developed by Zuo et al. [54], who used a simple cubic lattice with a set of allowed interactions between nearest neighbor pairs. With this simple model, utilizing two excited $\mathrm{Er}^{3+}$ states, combined with one excited $\mathrm{Yb}^{3+}$ state, the authors could accurately predict the excitation dynamics inside a particle, even for a multi-layer design. This indicates that such an approach is feasible. Here, we expand this model to three excited states of $\mathrm{Er}^{3+}$, with the overall goal to distinguish between two-photonic and three-photonic UC processes. The radiative rate constants used in our model were obtained from $\beta$-material and are therefore host-specific [66]. Zuo et al. reported ET rates for $\beta$-material in 2018 [54], which were used by us as well.

Figure S13 in the ESM illustrates the involved interactions and allowed energy states used in our Monte Carlo model. The simulation allows energy migration only on the $980 \mathrm{~nm}$ energy levels of $\mathrm{Yb}^{3+}$ and $\mathrm{Er}^{3+}$ and ET from the $980 \mathrm{~nm}$ energy levels to other excited states of $\mathrm{Er}^{3+}$. The emission from state " 5 " (accessible by a two-photonic process) is ascribed to the green emission and that from state "6" (accessible by a three-photonic process) to the red luminescence, even though in the real $\mathrm{Er}^{3+}$ system the actual red emissive state is energetically lower than the green energy level. For simplicity, we omitted non-radiative relaxation processes and BET that contribute to the three-photonic population of the red emissive state. We also sum up all three-photonic emissions and refer to them as "red" and all two-photonic emissions as "green." We deliberately focus here only on these two luminescence bands, although there are other non-negligible twoand three-photonic emissions in the real system besides the green and red emission.

Our simulation also includes surface quenching. If an electronically excited emissive $\mathrm{Ln}^{3+}$ ion is located at the surface, ET to a quencher is possible, resulting in a loss of excitation energy. To demonstrate a volume effect without any influence of the surface, we assume a perfect surface passivation, setting the surface

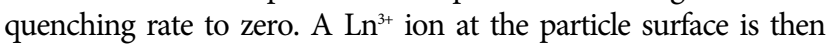
simply characterized by fewer energy transfer partners. To create a 
more realistic model, the particles are assumed to be spherical instead of cubic, so that $\mathrm{Ln}^{3+}$ ions at the particle surface can have up to three quenchers as nearest neighbors, due to the cubic crystal lattice assumed in the model used. A thorough assessment of the model is detailed in the ESM. All parameters and steps used are listed in Table S4 and Fig. S15 in the ESM.

\subsection{P-dependent measurements: theory and experiment}

The results of the $P$-dependent measurements performed with a custom-built integrating sphere setup [58] are displayed in Fig. 6(a) (shell series) and Fig.6(b) (size series). To ease the comparison of the experimental data to our model used for the simulation, all mostly two-photonic processes (green emission, and NIR emission bands centered at 810 and $845 \mathrm{~nm}$ ), and all mostly three-photonic processes (blue and red emission) are each summed up. In the simulation, the radiative rates of the $7 \mathrm{~nm}$ core/shell YbErNC $\left(d_{\mathrm{S}}=3 \mathrm{~nm}\right)$ are used for the simulation of the shell series (cf. Table S4 in the ESM). To consider surface quenching, the surface quenching rate reported by Zuo et al. [54] is multiplied by a factor $Q$, thereby varying the surface quenching rate from $0 \%$ to $100 \%$ of Zuo's value (quenching factors $Q=0$ and $Q=1$ ) to account for the diminishing surface quenching with increasing shell thickness (Fig. 6(c)). The simulated $7 \mathrm{~nm}$ particle yields very low numbers of emitted photons, causing statistical noise in the data. For the simulation of the experimental size series, the radiative rates of the $30 \mathrm{~nm}$ unshelled $\mathrm{YbErNC}$ are employed in the simulation. The size of the simulated particle is varied from 7 to $30 \mathrm{~nm}$, while surface quenching is neglected $(Q=0)$. This leads to different $P$-dependent green-to-red ratios, even though no parameters except for the particle size, and thereby the number of active $\mathrm{Ln}^{3+}$ ions in the core, are changed (Fig. 6(d)).

As revealed by our experimental studies, even at low $P$, where all luminescence bands originate merely from two-photonic processes, there is a constant contribution of about $20 \%$ of the red $\mathrm{Er}^{3+}$ emission. Therefore, we decided to consider this contribution in the simulation of the luminescence data as an offset. The experimental results of the shell series summarized in Fig. 6(a) show how the surface passivation of a $7 \mathrm{~nm}$ YbErNC increases the luminescence arising from three-photonic processes. A slight increase of the contribution of three photonic processes and the respective luminescence is also observed at higher $P$, but even at the maximum $P$ of $56 \mathrm{~W} / \mathrm{cm}^{2}$ (indicated by a dashed grey line in Figs. 6(c) and 6(d)) used in this study, the emission of the $7 \mathrm{~nm}$ core/shell $\mathrm{YbErNC}\left(d_{\mathrm{s}}=3 \mathrm{~nm}\right)$ is dominated by a green luminescence and two-photonic processes. The simulated quenching series ( $Q$ series, see Fig. 6(c)) shows the same trend. The more pronounced the surface quenching is (up to $Q=1$ ), the higher is the contribution of the two-photonic luminescence to the overall UCL. At higher $P$, the theoretically and experimentally determined contribution of the luminescence originating from two- and three-photonic processes seems to be comparable. For an ideal, perfectly passivated, defect-free $\operatorname{YbErNC}(Q=0)$ the contribution of the red emission is slightly higher in the simulation than experimentally measured for our $7 \mathrm{~nm}$ core/shell $\operatorname{YbErNC}\left(d_{\mathrm{S}}=3 \mathrm{~nm}\right)$.

The experimental data derived for the unshelled size series (Fig. 6(b)), however, reveals a different picture than the shell series with its dominant green luminescence. With increasing particle size, the contribution of the red emission increases even at low $P$.
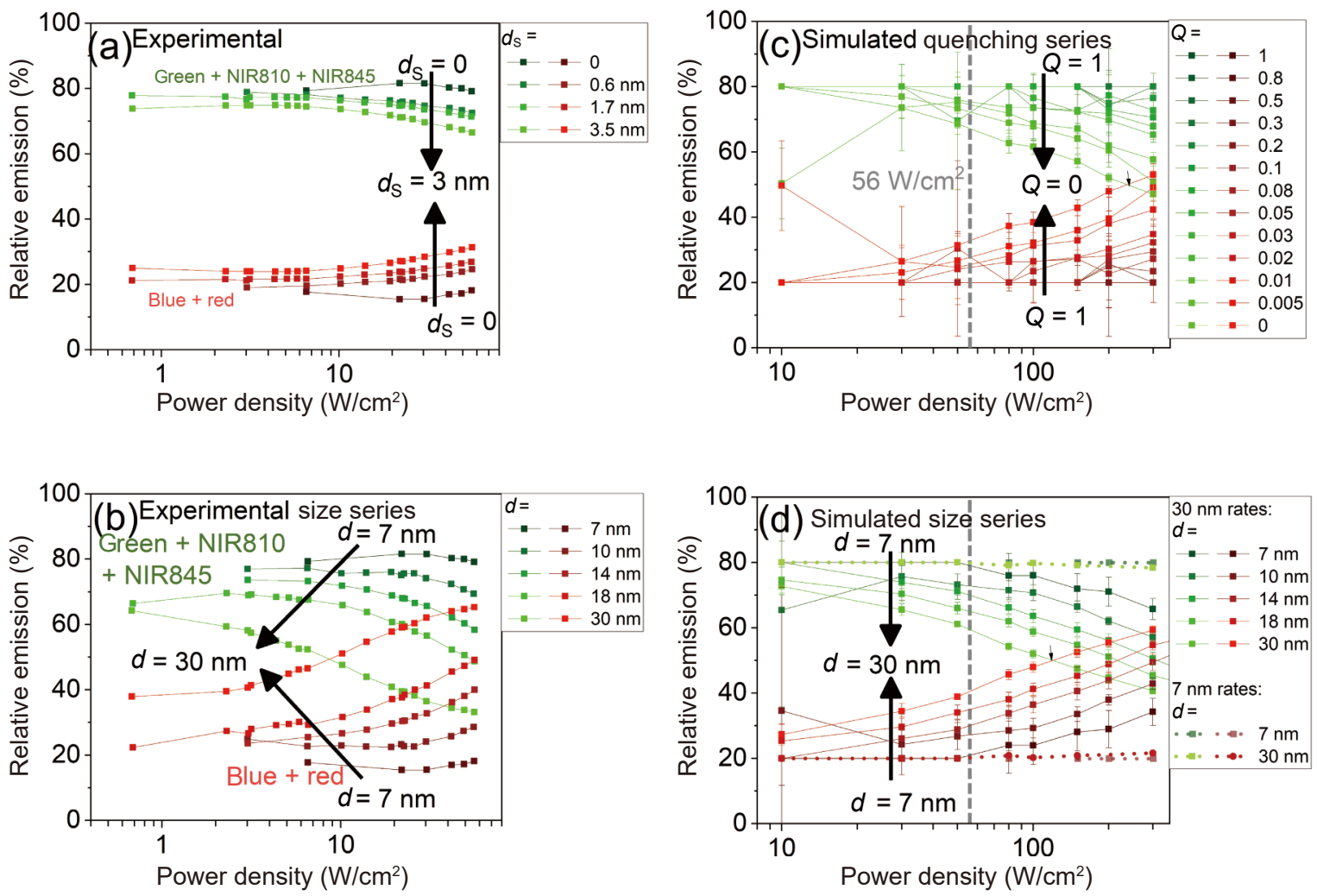

Figure 6 Experimentally-obtained and simulated $P$-dependent relative two- and three-photonic emission intensities of the YbErNC. The experimental results are given in (a) for the shell series (7 $\mathrm{nm}$ core) and (b) for the size series, measured as powder and under continuous $976 \mathrm{~nm}$ excitation. (c) For the simulation, the radiative rates derived for the $7 \mathrm{~nm}$ core/shell YbErNC $\left(d_{\mathrm{S}}=3 \mathrm{~nm}\right)$ are used, the particle size is set to $7 \mathrm{~nm}$, and surface quenching is varied from $0 \%$ to $100 \%$ (simulated $Q$ series). (d) The particle size in the simulation is varied from 7 to $30 \mathrm{~nm}$ (the same range as covered by the experimentally assessed size series), using the radiative rates obtained for the $30 \mathrm{~nm}$ unshelled YbErNC and zero surface quenching (simulated size series). Since the simulation views the red emission as being purely three-photonic, a constant offset of $20 \%$ was added to the red luminescence to account for the two-photonic contribution of the red emission. Dashed lines and lighter color shades are used to visualize the results of the simulation using the emissive rates of the unshelled $7 \mathrm{~nm}$ particle. 
For the largest $(30 \mathrm{~nm})$ particles of this series, the green/twophotonic and red/three-photonic emissions amount to equal relative intensities at $P$ of about $8 \mathrm{~W} / \mathrm{cm}^{2}$. Although the simulation reveals a crossing point at a different, higher $P$ (Fig. 6(d)), indicating the need to further fine-tune our simulations, the results of the simulation show the same trend as the experimental data. Simulating the luminescence of the 7 and $30 \mathrm{~nm} \mathrm{YbErNC}$ using the radiative rates obtained for the unshelled $7 \mathrm{~nm}$ YbErNC, the contribution of the red/three-photonic emission is largely reduced (see results indicated in Fig. 6(d) as dashed lines in a lighter color shade). Overall, our simulations confirm the existence of a volume effect and the impact of the total number of active $\mathrm{Ln}^{3+}$ ions present in the particle.

For the simulations using the given radiative rates and the simplified geometry, the mean pathlength of the excitation energy inside an unquenched particle exceeds $100 \mathrm{~nm}$ (Figs. S17 and S18 in the ESM). This implies that the energy of every absorbed photon can cross the entire particle several times in this model before being transferred to a higher $\mathrm{Er}^{3+}$ energy level. Thereby, the total number of $\mathrm{Ln}^{3+}$ ions inside the particle determines how many photons can contribute to $\mathrm{Er}^{3+}$ excitation and with an increasing number of $\mathrm{Yb}^{3+}$ (and $\mathrm{Er}^{3+}$ ) ions, the number of exited $\mathrm{Ln}^{3+}$ ions automatically increases and higher order photonic processes become more likely. Please note that this should not be confused with the effects to be expected for increasing $\mathrm{Ln}^{3+}$ doping concentrations and subsequent reduction of the mean ion-ion distance, which results in higher ET rates (due to the $d^{6}$ dependence of a Förster-type ET) and simultaneously, a possibly drastic increase in nonradiative $\mathrm{CR}$ processes. Our work comprises size and surface quenching variations while maintaining doping concentrations of $20 \% \mathrm{Yb}^{3+}$ and $2 \% \mathrm{Er}^{3+}$, which results in a mean ion-ion distance of $6.9 \AA$ in the $\beta-\mathrm{NaYF}_{4}$ host lattice [67]. Decreasing this distance, for example by introducing higher $\mathrm{Yb}^{3+}$ doping concentrations, would enable an even more efficient population of the red emission (FRET between $\mathrm{Ln}^{3+}$ ions), especially at low $P$, while the effect of surface quenching of the directly excited $\mathrm{Er}^{3+}$ states (FRET to surface ligands) is expected to depend on the $\mathrm{Er}^{3+}-\mathrm{Er}^{3+}$ distances.

We observe a rather constant mean excitation pathlength with respect to $P$ for the simulation with the radiative rates derived for the $7 \mathrm{~nm} \mathrm{YbErNC} \mathrm{(Fig.} \mathrm{S18(a)} \mathrm{in} \mathrm{the} \mathrm{ESM)} \mathrm{and} \mathrm{a} \mathrm{decrease} \mathrm{of} \mathrm{the}$ mean excitation pathlength for increasing $P$. The latter becomes more pronounced with increasing size for the simulation using the radiative rates from the $30 \mathrm{~nm}$ YbErNC (Fig. S17(b) in the ESM). The quenched system is $P$-independent while an unquenched system shows a $P$ dependence with shorter mean pathlengths for higher $P$ due to the accordingly increased probability of a multiphotonic excitation of an $\mathrm{Er}^{3+}$ ion by the generally enhanced number of excited ions in the particle lattice. Extrapolating from Fig. S17(a) in the ESM, a drastic decrease of the mean excitation pathlength can be expected for even higher $P$. This suggests that surface quenching might not play a significant role in measurements done at very high $P$, for example using confocal microscopes.

Even though we did not implement surface quenching in the model $(Q=0)$, smaller particles reveal a higher green-to-red ratio than the larger ones, independent of the set of radiative rates chosen for the simulation (see Fig. S19 in the ESM). For Fig. S19 in the ESM the same set of parameters was used, except for the particle size, which determines the total number of ions. Thereby, it becomes evident that besides surface quenching, there is a second size-related quenching effect, namely a volume effect.

\section{Conclusions and outlook}

We examined the steady-state and time-resolved luminescence of a set of single $\mathrm{Yb}^{3+}$ - or $\mathrm{Er}^{3+}$-doped and $\mathrm{Yb}^{3+}, \mathrm{Er}^{3+}$-co-doped small core and core/shell NC of comparable size made from the most efficient host matrix $\beta-\mathrm{NaYF}_{4}$ according to broadly used, representative synthetic procedures and compared their luminescence features to those of micrometer-sized phosphor powders of the same chemical composition (denoted as Yb-Bulk, Er-Bulk, and YbEr-Bulk). Excitation was done at $978 \mathrm{~nm}$, thereby directly exciting the sensitizer $\mathrm{Yb}^{3+}$ and monitoring either the downshifted emission of $\mathrm{Yb}^{3+}$ at $940 \mathrm{~nm}$ or the differently colored $\mathrm{Er}^{3+} \mathrm{UCL}$ of the UCNC, originating mainly from ETU. Excitation was also done at $375 \mathrm{~nm}$, thereby directly exciting $\mathrm{Er}^{3+}$ and detecting its multicolor emission at different wavelengths. Special emphasis was dedicated to the green and red emission of $\mathrm{Er}^{3+}$ at 540 and $655 \mathrm{~nm}$ originating from the ${ }^{4} \mathrm{~S}_{3 / 2}$ and ${ }^{4} \mathrm{~F}_{9 / 2} \mathrm{Er}^{3+}$ energy levels, which are populated either by a simple two-photonic process or a mixture of two- and three-photonic processes.

Based upon ( $P$-dependent luminescence studies with these size and shell series at different excitation and emission wavelengths, we were able to separate the contribution of surface-related and volume-related effects to the overall emission behavior of $\mathrm{Yb}^{3+}, \mathrm{Er}^{3+}$ -doped UCNC. These effects are highlighted by different red to green ratios of the $\mathrm{Er}^{3+}$ emission in the P-dependent and timeresolved luminescence measurements. For the particles (powder) studied, the surface ligands play an important role. Apparently, the red emissive ${ }^{4} \mathrm{~F}_{9 / 2} \mathrm{Er}^{3+}$ energy level is stronger affected by the $-\mathrm{CH}$ vibrations of oleic acid than the green emitting ${ }^{2} \mathrm{H}_{11 / 2} /{ }^{4} \mathrm{~S}_{3 / 2}$ $\mathrm{Er}^{3+}$ energy level and the excited $\mathrm{Yb}^{3+}$ energy level. With the aid of a previously described and refined quenching layer model, we could ascribe our observations to different thicknesses of the respective color-specific quenching layers arising from different Förster distances for the underlying ET processes involving the particle surface. The volume effect is related to the number of active lanthanide $\left(\mathrm{Ln}^{3+}\right)$ ions participating in the different excitation processes and excitation energy migration, as the number of threephotonic excitations, and therefore the efficient population of the red-emissive ${ }^{4} \mathrm{~F}_{9 / 2}$ state of $\mathrm{Er}^{3+}$, mainly increases with increasing particle volume, and only slightly with shell thickness for a constant volume of the active core. By comparing the results of a Monte Carlo simulation and three-dimensional random walk model, which considers one excited $\mathrm{Yb}^{3+}$ state and three excited $\mathrm{Er}^{3+}$ states, with our experimental data, we could demonstrate the potential of this simple simulation to predict the trends of the excitation dynamics inside a particle and thereby the $P$-dependent UCL characteristics and the contribution of two- and threephotonic processes to the generation of UCL. Currently, we are further fine-tuning our Monte Carlo model to simulate the different population processes in $\mathrm{Yb}^{3+}, \mathrm{Er}^{3+}$-co-doped $\mathrm{UC}$ materials and rationally design UCNC with optimum performance in different application-relevant $P$ regimes.

\section{Acknowledgements}

The authors gratefully acknowledge financial support from the German Science Foundation (DFG; Nos. RE 1203/18-1 and HA 1649/7-1). We thank Professor Th. Jüstel (FH Münster, Steinfurt) for providing the microcrystalline powder phosphors Yb-Bulk $\left(\mathrm{NaYF}_{4}: \mathrm{Yb}\right)$ and Er-Bulk $\left(\mathrm{NaYF}_{4}: \mathrm{Er}\right)$ and Dr. K. Krämer (University of Bern, Switzerland) for provision of the microcrystalline $\mathrm{NaYF}_{4}: \mathrm{Yb} \mathrm{UC}$ phosphor.

Funding note Open Access funding enabled and organized by Projekt DEAL. 
Electronic Supplementary Material: Supplementary material (detailed synthesis procedure, TEM images, spectroscopic data, detailed description of the Monte Carlo simulation) is available in the online version of this article at https://doi.org/10.1007/s12274021-3727-y.

\section{References}

[1] Zhou, J. J.; Leaño, J. L. Jr.; Liu, Z. Y.; Jin, D. Y.; Wong, K. L.; Liu, R. S.; Bünzli, J. C. G. Impact of lanthanide nanomaterials on photonic devices and smart applications. Small 2018, 14, 1801882.

[2] Gai, S. L.; Li, C. X.; Yang, P. P.; Lin, J. Recent progress in rare earth micro/nanocrystals: Soft chemical synthesis, luminescent properties, and biomedical applications. Chem. Rev. 2014, 114, 2343-2389.

[3] Zhang, Z. M.; Shikha, S.; Liu, J. L.; Zhang, J.; Mei, Q. S.; Zhang, Y. Upconversion nanoprobes: Recent advances in sensing applications. Anal. Chem. 2019, 91, 548-568.

[4] Resch-Genger, U.; Gorris, H. H. Perspectives and challenges of photon-upconversion nanoparticles-Part I: routes to brighter particles and quantitative spectroscopic studies. Anal. Bioanal. Chem. 2017, 409, 5855-5874.

[5] Gu, B.; Zhang, Q. C. Recent advances on functionalized upconversion nanoparticles for detection of small molecules and ions in biosystems. $A d v$. Sci. 2018, 5, 1700609.

[6] Liu, Q.; Feng, W.; Li, F. Y. Water-soluble lanthanide upconversion nanophosphors: Synthesis and bioimaging applications in vivo. Coord. Chem. Rev. 2014, 273-274, 100.

[7] Zhang, Y.; Wei, W.; Das, G. K.; Tan, T. T. Y. Engineering lanthanide-based materials for nanomedicine. $J$. Photochem.Photobiol C: Photochem. Rev. 2014, 20, 71-96.

[8] Chen, G. Y.; Ågren, H.; Ohulchanskyy, T. Y.; Prasad, P. N. Light upconverting core-shell nanostructures: Nanophotonic control for emerging applications. Chem. Soc. Rev. 2015, 44, 1680-1713.

[9] Gorris, H. H.; Resch-Genger, U. Perspectives and challenges of photon-upconversion nanoparticles-Part II: Bioanalytical applications. Anal. Bioanal. Chem. 2017, 409, 5875-5890.

[10] Haase, M.; Schäfer, H. Upconverting nanoparticles. Angew. Chem., Int. Ed. 2011, 50, 5808-5829.

[11] Liu, Y. J.; Lu, Y. Q.; Yang, X. S.; Zheng, X. L.; Wen, S. H.; Wang, F.; Vidal, X.; Zhao, J. B.; Liu, D. M.; Zhou, Z. G. et al. Amplified stimulated emission in upconversion nanoparticles for superresolution nanoscopy. Nature 2017, 543, 229-233.

[12] Goldschmidt, J. C.; Fischer, S. Upconversion for photovoltaics-a review of materials, devices and concepts for performance enhancement. Adv. Opt. Mater. 2015, 3, 510-535.

[13] Fernandez-Bravo, A.; Yao, K. Y.; Barnard, E. S.; Borys, N. J.; Levy, E. S.; Tian, B. N.; Tajon, C. A.; Moretti, L.; Altoe, M. V.; Aloni, S. et al. Continuous-wave upconverting nanoparticle microlasers. Nat. Nanotech. 2018, 13, 572-577.

[14] Arppe, R.; Sørensen, T. J. Physical unclonable functions generated through chemical methods for anti-counterfeiting. Nat. Rev. Chem. 2017, 1, 0031.

[15] Kumar, P.; Singh, S.; Gupta, B. K. Future prospects of luminescent nanomaterial based security inks: From synthesis to anticounterfeiting applications. Nanoscale 2016, 8, 14297-14340.

[16] Shikha, S.; Salafi, T.; Cheng, J. T.; Zhang, Y. Versatile design and synthesis of nano-barcodes. Chem. Soc. Rev. 2017, 46, 7054-7093.

[17] Wen, S. H.; Zhou, J. J.; Zheng, K. Z.; Bednarkiewicz, A.; Liu, X. G.; Jin, D. Y. Advances in highly doped upconversion nanoparticles. Nat. Commun. 2018, 9, 2415.

[18] Qin, X.; Xu, J. H.; Wu, Y. M.; Liu, X. G. Energy-transfer editing in lanthanide-activated upconversion nanocrystals: A toolbox for emerging applications. ACS Cent. Sci. 2019, 5, 29-42.

[19] Li, H.; Wang, X.; Li, X. L.; Zeng, S. J.; Chen, G. Y. Clearable shortwave-infrared-emitting $\mathrm{NaErF}_{4}$ nanoparticles for noninvasive dynamic vascular imaging. Chem. Mater. 2020, 32, 3365-3375.

[20] Hemmer, E.; Benayas, A.; Légaré, F.; Vetrone, F. Exploiting the biological windows: Current perspectives on fluorescent bioprobes emitting above $1000 \mathrm{~nm}$. Nanoscale Horiz. 2016, 1, 168-184.

[21] Tu, L. P.; Liu, X. M.; Wu, F.; Zhang, H. Excitation energy migration dynamics in upconversion nanomaterials. Chem. Soc. Rev. 2015, 44, 1331-1345.

[22] Auzel, F. Upconversion and anti-stokes processes with $\mathrm{f}$ and $\mathrm{d}$ ions in solids. Chem. Rev. 2004, 104, 139-173.

[23] Joseph, R. E.; Jiménez, C.; Hudry, D.; Gao, G. J.; Busko, D.; Biner, D.; Turshatov, A.; Krämer, K.; Richards, B. S.; Howard, I. A. Critical power density: A metric to compare the excitation power density dependence of photon upconversion in different inorganic host materials. J. Phys. Chem. A 2019, 123, 6799-6811.

[24] Chen, B.; Wang, F. Recent advances in the synthesis and application of Yb-based fluoride upconversion nanoparticles. Inorg. Chem. Front. 2020, 7, 1067-1081.

[25] Chen, B.; Wang, F. Combating concentration quenching in upconversion nanoparticles. Acc. Chem. Res. 2020, 53, 358-367.

[26] Wang, Z. J.; Meijerink, A. Concentration quenching in upconversion nanocrystals. J. Phys. Chem. C 2018, 122, 26298-26306.

[27] Homann, C.; Krukewitt, L.; Frenzel, F.; Grauel, B.; Würth, C.; ReschGenger, U.; Haase, M. $\mathrm{NaYF}_{4}$ : $\mathrm{Yb}, \mathrm{Er} / \mathrm{NaYF}_{4}$ core/shell nanocrystals with high upconversion luminescence quantum yield. Angew. Chem., Int. Ed. 2018, 57, 8765-8769.

[28] Rabouw, F. T.; Prins, P. T.; Villanueva-Delgado, P.; Castelijns, M.; Geitenbeek, R. G.; Meijerink, A. Quenching pathways in $\mathrm{NaYF}_{4}$ : $\mathrm{Er}^{3+}, \mathrm{Yb}^{3+}$ upconversion nanocrystals. ACS Nano 2018, 12, $4812-4823$

[29] Hu, Y. Q.; Shao, Q. Y.; Dong, Y.; Jiang, J. Q. Energy loss mechanism of upconversion core/shell nanocrystals. J. Phys. Chem. C 2019, 123, 22674-22679.

[30] Su, Q. Q.; Han, S. Y.; Xie, X. J.; Zhu, H. M.; Chen, H. Y.; Chen, C. K.; Liu, R. S.; Chen, X. Y.; Wang, F.; Liu, X. G. The effect of surface coating on energy migration-mediated upconversion. J. Am. Chem. Soc. 2012, 134, 20849-20857.

[31] Würth, C.; Fischer, S.; Grauel, B.; Alivisatos, A. P.; Resch-Genger, U. Quantum yields, surface quenching, and passivation efficiency for ultrasmall core/shell upconverting nanoparticles. J. Am. Chem. Soc. 2018, 140, 4922-4928.

[32] Würth, C.; Kaiser, M.; Wilhelm, S.; Grauel, B.; Hirsch, T.; ReschGenger, U. Excitation power dependent population pathways and absolute quantum yields of upconversion nanoparticles in different solvents. Nanoscale 2017, 9, 4283-4294.

[33] Boyer, J. C.; Van Veggel, F. C. J. M. Absolute quantum yield measurements of colloidal $\mathrm{NaYF}_{4}: \mathrm{Er}^{3+}, \mathrm{Yb}^{3+}$ upconverting nanoparticles. Nanoscale 2010, 2, 1417-1419.

[34] Vetrone, F.; Boyer, J. C.; Capobianco, J. A.; Speghini, A.; Bettinelli, $\mathrm{M}$. Concentration-dependent near-infrared to visible upconversion in nanocrystalline and bulk $\mathrm{Y}_{2} \mathrm{O}_{3}: \mathrm{Er}^{3+}$. Chem. Mater. 2003, 15, $2737-2743$.

[35] Vetrone, F.; Boyer, J. C.; Capobianco, J. A.; Speghini, A.; Bettinelli, M. Significance of $\mathrm{Yb}^{3+}$ concentration on the upconversion mechanisms in codoped $\mathrm{Y}_{2} \mathrm{O}_{3}: \mathrm{Er}^{3+}, \mathrm{Yb}^{3+}$ nanocrystals. J. Appl. Phys. 2004, 96, 661-667.

[36] Martín-Rodríguez, R.; Rabouw, F. T.; Trevisani, M.; Bettinelli, M.; Meijerink, A. Upconversion dynamics in $\mathrm{Er}^{3+}$-doped $\mathrm{Gd}_{2} \mathrm{O}_{2} \mathrm{~S}$ : influence of excitation power, $\mathrm{Er}^{3+}$ concentration, and defects. $A d v$. Opt. Mater. 2015, 3, 558-567.

[37] Abel, K. A.; Boyer, J. C.; Andrei, C. M.; Van Veggel, F. C. J. M. Analysis of the shell thickness distribution on $\mathrm{NaYF}_{4} / \mathrm{NaGdF}_{4}$ core/shell nanocrystals by EELS and EDS. J. Phys. Chem. Lett. 2011, 2, 185-189.

[38] Johnson, N. J. J.; Van Veggel, F. C. J. M. Sodium lanthanide fluoride core-shell nanocrystals: A general perspective on epitaxial shell growth. Nano Res. 2013, 6, 547-561.

[39] Johnson, N. J. J.; Van Veggel, F. C. J. M. Lanthanide-based heteroepitaxial core-shell nanostructures: Compressive versus tensile strain asymmetry. ACS Nano 2014, 8, 10517-10527.

[40] Hudry, D.; Busko, D.; Popescu, R.; Gerthsen, D.; Abeykoon, A. M. M.; Kübel, C.; Bergfeldt, T.; Richards, B. S. Direct evidence of significant cation intermixing in upconverting core@shell nanocrystals: Toward a new crystallochemical model. Chem. Mater. 2017, 29, 9238-9246.

[41] Wang, F.; Deng, R. R.; Wang, J.; Wang, Q. X.; Han, Y.; Zhu, H. M.; 
Chen, X. Y.; Liu, X. G. Tuning upconversion through energy migration in core-shell nanoparticles. Nat. Mater. 2011, 10, 968-973.

[42] Quintanilla, M.; Ren, F. Q.; Ma, D. L.; Vetrone, F. Light management in upconverting nanoparticles: Ultrasmall core/shell architectures to tune the emission color. ACS Photonics 2014, 1, 662-669.

[43] Pilch, A.; Würth, C.; Kaiser, M.; Wawrzyńczyk, D.; Kurnatowska, M.; Arabasz, S.; Prorok, K.; Samoć, M.; Strek, W.; Resch-Genger, $\mathrm{U}$. et al. Shaping luminescent properties of $\mathrm{Yb}^{3+}$ and $\mathrm{Ho}^{3+}$ co-doped upconverting core-shell $\beta-\mathrm{NaYF}_{4}$ nanoparticles by dopant distribution and spacing. Small 2017, 13, 1701635.

[44] Huang, K.; Liu, H. C.; Kraft, M.; Shikha, S.; Zheng, X.; Ågren, H.; Würth, C.; Resch-Genger, U.; Zhang, Y. A protected excitationenergy reservoir for efficient upconversion luminescence. Nanoscale 2018, 10, 250-259.

[45] Li, X. M.; Wang, R.; Zhang, F.; Zhao, D. Y. Engineering homogeneous doping in single nanoparticle to enhance upconversion efficiency. Nano Lett. 2014, 14, 3634-3639.

[46] Li, X. M.; Shen, D. K.; Yang, J. P.; Yao, C.; Che, R. C.; Zhang, F.; Zhao, D. Y. Successive layer-by-layer strategy for multi-shell epitaxial growth: Shell thickness and doping position dependence in upconverting optical properties. Chem. Mater. 2013, 25, 106-112.

[47] Liu, J. F.; Fu, T. R.; Shi, C. L. Spatial energy transfer and migration model for upconversion dynamics in core-shell nanostructures. $J$. Phys. Chem. C 2019, 123, 9506-9515.

[48] Wang, F.; Liu, X. G. Upconversion multicolor fine-tuning: Visible to near-infrared emission from lanthanide-doped $\mathrm{NaYF}_{4}$ nanoparticles. J. Am. Chem. Soc. 2008, 130, 5642-5643.

[49] Hossan, M. Y.; Hor, A.; Luu, Q.; Smith, S. J.; May, P. S.; Berry, M. T. Explaining the nanoscale effect in the upconversion dynamics of $\beta$ $\mathrm{NaYF}_{4}: \mathrm{Yb}^{3+}, \mathrm{Er}^{3+}$ core and core-shell nanocrystals. J. Phys. Chem. C 2017, 121, 16592-16606.

[50] Berry, M. T.; May, P. S. Disputed mechanism for NIR-to-Red upconversion luminescence in $\mathrm{NaYF}_{4}: \mathrm{Yb}^{3+}, \mathrm{Er}^{3+}$. J. Phys. Chem. A 2015, 119, 9805-9811.

[51] Wang, F.; Liu, X. G. Recent advances in the chemistry of lanthanidedoped upconversion nanocrystals. Chem. Soc. Rev. 2009, 38, 976-989.

[52] Liu, X. G.; Yan, C. H.; Capobianco, J. A. Photon upconversion nanomaterials. Chem. Soc. Rev. 2015, 44, 1299-1301.

[53] Kraft, M.; Würth, C.; Muhr, V.; Hirsch, T.; Resch-Genger, U. Particle-size-dependent upconversion luminescence of $\mathrm{NaYF}_{4}$ : $\mathrm{Yb}$, Er nanoparticles in organic solvents and water at different excitation power densities. Nano Res. 2018, 11, 6360-6374.

[54] Zuo, J.; Sun, D. P.; Tu, L. P.; Wu, Y. N.; Cao, Y. H.; Xue, B.; Zhang, Y. L.; Chang, Y. L.; Liu, X. M.; Kong, X. G.; Buma, W. J. et al. Precisely tailoring upconversion dynamics via energy migration in core-shell nanostructures. Angew. Chem., Int. Ed. 2018, 57, 3054-3058

[55] Park, J.; An, K. J.; Hwang, Y. S.; Park, J. G.; Noh, H. J.; Kim, J. Y.; Park, J. H.; Hwang, N. M.; Hyeon, T. Ultra-large-scale syntheses of monodisperse nanocrystals. Nat. Mater. 2004, 3, 891-895.

[56] Rinkel, T.; Raj, A. N.; Dühnen, S.; Haase, M. Synthesis of $10 \mathrm{~nm} \beta$ $\mathrm{NaYF}_{4}: \mathrm{Yb}, \mathrm{Er} / \mathrm{NaYF}_{4}$ core/shell upconversion nanocrystals with 5 nm particle cores. Angew. Chem., Int. Ed. 2016, 55, 1164-1167.

[57] Rinkel, T.; Nordmann, J.; Raj, A. N.; Haase, M. Ostwald-ripening and particle size focussing of sub-10 nm $\mathrm{NaYF}_{4}$ upconversion nanocrystals. Nanoscale 2014, 6, 14523-14530.

[58] Kaiser, M.; Würth, C.; Kraft, M.; Hyppänen, I.; Soukka, T.; ReschGenger, $\mathrm{U}$. Power-dependent upconversion quantum yield of $\mathrm{NaYF}_{4}$ : $\mathrm{Yb}^{3+}, \mathrm{Er}^{3+}$ nano- and micrometer-sized particles - measurements and simulations. Nanoscale 2017, 9, 10051-10058.

[59] Anderson, R. B.; Smith, S. J.; May, P. S.; Berry, M. T. Revisiting the NIR-to-visible upconversion mechanism in $\beta-\mathrm{NaYF}_{4}: \mathrm{Yb}^{3+}, \mathrm{Er}^{3+} . J$. Phys. Chem. Lett. 2014, 5, 36-42.

[60] Ledoux, G.; Amans, D.; Joubert, M. F.; Mahler, B.; Mishra, S.; Daniele, S.; Dujardin, C. Modeling energy migration for upconversion materials. J. Phys. Chem. C 2018, 122, 888-893.

[61] Villanueva-Delgado, P.; Krämer, K. W.; Valiente, R. Simulating Energy Transfer and Upconversion in $\beta-\mathrm{NaYF}_{4}: \mathrm{Yb}^{3+}, \mathrm{Tm}^{3+} . J$. Phys. Chem. C 2015, 119, 23648-23657.

[62] Pawlik, G.; Niczyj, J.; Noculak, A.; Radosz, W.; Podhorodecki, A. Multiband Monte Carlo modeling of upconversion emission in sub $10 \mathrm{~nm} \beta-\mathrm{NaGdF}_{4}: \mathrm{Yb}^{3+}, \mathrm{Er}^{3+}$ nanocrystals-Effect of $\mathrm{Yb}^{3+}$ content. $J$. Chem. Phys. 2017, 146, 244111.

[63] Renero-Lecuna, C.; Martín-Rodríguez, R.; Valiente, R.; González J.; Rodríguez F.; Krämer K. W.; Güdel H. U. Origin of the high upconversion green luminescence efficiency in $\beta-\mathrm{NaYF}_{4}: 2 \% \mathrm{Er}^{3+}$, $20 \% \mathrm{Yb}^{3+}$. Chem. Mater. 2011, 23, 3442-3448.

[64] Aebischer, A.; Hostettler, M.; Hauser, J.; Krämer, K.; Weber, T.; Güdel, H. U.; Bürgi, H. B. Structural and spectroscopic characterization of active sites in a family of light-emitting sodium lanthanide tetrafluorides. Angew. Chem., Int. Ed. 2006, 45, 2802-2806.

[65] Grzechnik, A.; Friese, K. Crystal structures and stability of $\mathrm{NaLnF}_{4}$ $(\mathrm{Ln}=\mathrm{La}, \mathrm{Ce}, \mathrm{Pr}, \mathrm{Nd}, \mathrm{Sm}$ and $\mathrm{Gd})$ studied with synchrotron singlecrystal and powder diffraction. Dalton Trans. 2012, 41, 10258-10266.

[66] Fischer, S.; Mehlenbacher, R. D.; Lay, A.; Siefe, C.; Alivisatos, A. P.; Dionne, J. A. Small alkaline-earth-based core/shell nanoparticles for efficient upconversion. Nano Lett. 2019, 19, 3878-3885.

[67] Fischer, S.; Johnson, N. J. J.; Pichaandi, J.; Goldschmidt, J. C.; Van Veggel, F. C. J. M. Upconverting core-shell nanocrystals with high quantum yield under low irradiance: On the role of isotropic and thick shells. J. Appl. Phys. 2015, 118, 193105. 